\title{
Synthesis, Structure, and Compositional Tuning of the Layered Oxide Tellurides $\mathrm{Sr}_{2} \mathrm{MnO}_{2} \mathrm{Cu}_{2-x} \mathrm{Te}_{2}$ and $\mathrm{Sr}_{2} \mathrm{CoO}_{2} \mathrm{Cu}_{2} \mathrm{Te}_{2}$
}

\author{
Jack N. Blandy, ${ }^{\dagger}$, Dinah R. Parker, $^{\dagger}$ Simon J. Cassidy, ${ }^{\dagger}$ Daniel N. Woodruff, ${ }^{\dagger}$ Xiaoyu Xu, ${ }^{\dagger}$ \\ and Simon J. Clarke* ${ }^{*}$ (1) \\ ${ }^{\dagger}$ Department of Chemistry, University of Oxford, Inorganic Chemistry Laboratory, South Parks Road, Oxford OX1 3QR, United \\ Kingdom \\ ${ }^{\ddagger}$ Diamond Light Source Ltd., Harwell Science and Innovation Campus, Didcot OX11 0DE, United Kingdom
}

\section{Supporting Information}

ABSTRACT: The synthesis and structure of two new transition metal oxide tellurides, $\mathrm{Sr}_{2} \mathrm{MnO}_{2} \mathrm{Cu}_{1.82(2)} \mathrm{Te}_{2}$ and $\mathrm{Sr}_{2} \mathrm{CoO}_{2} \mathrm{Cu}_{2} \mathrm{Te}_{2}$, are reported. $\mathrm{Sr}_{2} \mathrm{CoO}_{2} \mathrm{Cu}_{2} \mathrm{Te}_{2}$ with the purely divalent $\mathrm{Co}^{2+}$ ion in the oxide layers has magnetic ordering based on antiferromagnetic interactions between nearest neighbors and appears to be inert to attempted topotactic oxidation by partial removal of the $\mathrm{Cu}$ ions. In contrast, the $\mathrm{Mn}$ analogue with the more oxidizable transition metal ion has a 9(1)\% Cu deficiency in the telluride layer when synthesized at high temperatures, corresponding to a $\mathrm{Mn}$ oxidation state of $+2.18(2)$, and neutron powder diffraction revealed the presence of a sole highly asymmetric Warren-type magnetic peak, characteristic of magnetic ordering that is highly two-dimensional and not fully developed over a long range. Topotactic oxidation by the chemical deintercalation of further copper using a solution of $\mathrm{I}_{2}$ in acetonitrile offers control over the Mn oxidation state and, hence, the magnetic ordering: oxidation yielded $\mathrm{Sr}_{2} \mathrm{MnO}_{2} \mathrm{Cu}_{1.58(2)} \mathrm{Te}_{2}(\mathrm{Mn}$ oxidation state of $+2.42(2))$ in which ferromagnetic interactions between $\mathrm{Mn}$ ions result from $\mathrm{Mn}^{2+/ 3+}$ mixed valence, resulting in a long-range-ordered $A$-type antiferromagnet with ferromagnetic $\mathrm{MnO}_{2}$ layers coupled antiferromagnetically.

\section{INTRODUCTION}

Much of the focus in solid-state chemistry has been on transition metal and main group oxides, due to their ready synthesis under ambient air, and these have diverse behaviors with a range of important chemical, electronic, magnetic and ionic transport properties. Compounds containing two or more anions are less common, but these have received increasing prominence in recent years with the discovery of layered iron oxide arsenide superconductors. If the two anions are of similar size and polarizability, as in oxynitrides, oxyfluorides or nitride fluorides, then the anions tend to occupy the same or similar crystallographic sites. However, in cases where the anions are oxide and a heavier chalcogenide, such as S, Se, or Te, the two different anions with different sizes and chemistry will occupy different sites in the compound. ${ }^{1}$ This often leads to the formation of layered crystal structures. Examples are the compositionally diverse $A_{2} M_{2} M_{2}^{\prime}{ }_{2} h_{2}(A=S r, B a ; M=$ mid to late first row transition metal; $M^{\prime}=\mathrm{Cu}, \mathrm{Ag} ; \mathrm{Ch}=\mathrm{S}$, Se, Te) class of compounds. In these compounds the chalcophilic coinage-metal ions $\left(\mathrm{Cu}^{+}, \mathrm{Ag}^{+}\right)$and the chalcogenide ions segregate into one layer, while the transition metal and oxide ions segregate into the other, as shown in Figure 1 for the title compounds. ${ }^{2,3}$

These compounds have a vast array of properties, from $\mathrm{Sr}_{2} \mathrm{ZnO}_{2} \mathrm{Cu}_{2} \mathrm{~S}_{2}$, which is a bright yellow direct band gap
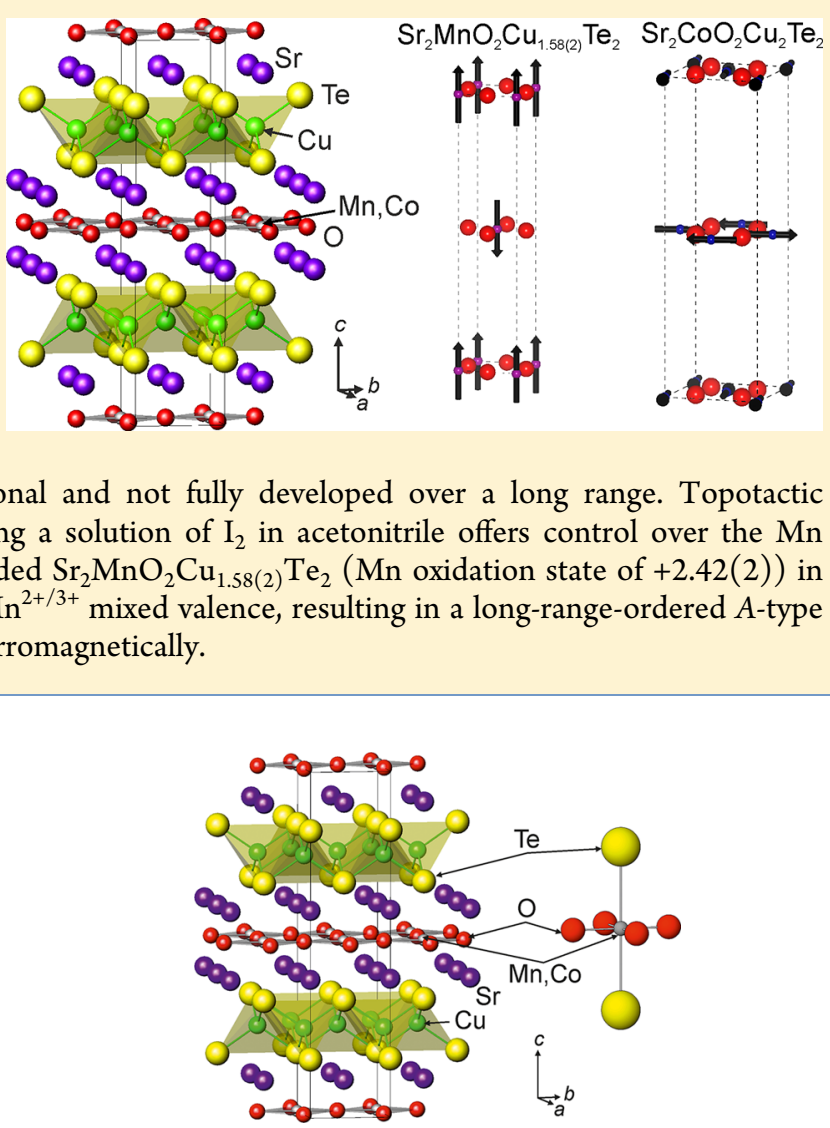

Figure 1. Crystal structure of $\mathrm{Sr}_{2} \mathrm{MO}_{2} \mathrm{Cu}_{2} \mathrm{Te}_{2}, M=\mathrm{Mn}$, Co with the detail of the distended coordination environment of the transition metal ion shown.

semiconductor, ${ }^{2}$ to $\mathrm{Sr}_{2} \mathrm{MnO}_{2} \mathrm{Cu}_{1.5} \mathrm{~S}_{2}$, a mixed-valent $\mathrm{Mn}$ compound that exhibits both copper-vacancy ordering on cooling due to the high coinage metal ion mobility and the high concentration of coinage metal site vacancies in the sulfide layer, and long-range magnetic ordering in which ferromagnetic interactions between $\mathrm{Mn}$ ions are promoted by mixed valence. ${ }^{4}$ Although the identity of the transition metal in

Received: March 29, 2019

Published: June 5, 2019 
the oxide layer dominates the physical properties of these compounds, isovalent substitutions of the other elements in the compound have nontrivial effects on the observed properties. Smura et al. showed that substitution of $\mathrm{Sr}$ by $\mathrm{Ba}$ in the solid solution $\mathrm{Sr}_{2-x} \mathrm{Ba}_{x} \mathrm{CoO}_{2} \mathrm{Cu}_{2} \mathrm{~S}_{2}$ dramatically increased the size of the ordered magnetic moment in the antiferromagnetic state. ${ }^{5}$ This was attributed to an increase in the orbital contribution to the magnetic moment of $\mathrm{Co}^{2+}$ by increasing the axial distention of the $\mathrm{CoO}_{4} \mathrm{~S}_{2}$ ligand field, ${ }^{5}$ and the effects have been replicated in $\mathrm{Sr}_{2} \mathrm{CoO}_{2} \mathrm{Ag}_{2} \mathrm{Se}_{2}$ and $\mathrm{Ba}_{2} \mathrm{CoO}_{2} \mathrm{Ag}_{2} \mathrm{Se}_{2}$. ${ }^{6}$

Isovalent substitutions on the chalcogenide site also influence the structural and physical properties. While the copper-site vacancies in $\mathrm{Sr}_{2} \mathrm{MnO}_{2} \mathrm{Cu}_{1.5} \mathrm{~S}_{2}$ order on cooling, ${ }^{4}$ no analogous long-range structural ordering is observed in the selenide analogue $\mathrm{Sr}_{2} \mathrm{MnO}_{2} \mathrm{Cu}_{1.5} \mathrm{Se}_{2}$, ${ }^{4}$ and this may be a consequence of lower $\mathrm{Cu}$ mobility in the selenide layer than in the sulfide layer in these compounds. Consistent with this, it was also found that, while copper could be topotactically deintercalated from $\mathrm{Sr}_{2} \mathrm{MnO}_{2} \mathrm{Cu}_{1.5} \mathrm{~S}_{2}$ at ambient temperatures to produce $\mathrm{Sr}_{2} \mathrm{MnO}_{2} \mathrm{Cu}_{1.33} \mathrm{~S}_{2}$, with a complex incommensurately modulated structure with copper/vacancy ordering at room temperature, ${ }^{7} \mathrm{Sr}_{2} \mathrm{MnO}_{2} \mathrm{Cu}_{1.5} \mathrm{Se}_{2}{ }^{8}$ and $\mathrm{Sr}_{2} \mathrm{MnO}_{2} \mathrm{Ag}_{1.5} \mathrm{Se}_{2}{ }^{9}$ were found to be inert to deintercalation when iodine in solution in acetonitrile at ambient temperatures was used as the reagent. While $\mathrm{Cu}^{+}$mobilities are similar in $\mathrm{Cu}_{2} \mathrm{~S}$ and $\mathrm{Cu}_{2} \mathrm{Se}^{10}$ measurements of the $\mathrm{Cu}^{+}$ion mobilities in these layered oxide chalcogenide compounds would be needed to determine whether this is a kinetic effect.

Here we describe the synthesis and properties of members of the $\mathrm{Sr}_{2} \mathrm{MO}_{2} \mathrm{Cu}_{2} \mathrm{Ch}_{2}$ series that contain telluride ions. This was motivated by the fact that while sulfide and selenide are fairly similar due to the insertion between them into the periodic table of the $3 d$ elements, telluride is much larger and more readily oxidized. The target compositions were $\mathrm{Sr}_{2} \mathrm{MnO}_{2} \mathrm{Cu}_{2} \mathrm{Te}_{2}$ and $\mathrm{Sr}_{2} \mathrm{CoO}_{2} \mathrm{Cu}_{2} \mathrm{Te}_{2}$. We describe the facile stabilization of a lower $\mathrm{Mn}$ oxidation state in the oxide telluride compared with that in the oxide sulfide and oxide selenide, ${ }^{4}$ which leads to quite different magnetic properties and then show that control of the $\mathrm{Mn}$ oxidation state is possible in this case by oxidative deintercalation of $\mathrm{Cu}$, turning on magnetic behavior similar to that in the analogues with the lighter chalcogenides. In contrast, $\mathrm{Sr}_{2} \mathrm{CoO}_{2} \mathrm{Cu}_{2} \mathrm{Te}_{2}$, with the less-easily oxidized $\mathrm{Co}^{2+}, 11$ has no deficiency in the coinage metal site occupancy within experimental uncertainty and is unreactive with respect to attempted oxidative deintercalation using $\mathrm{I}_{2}$.

\section{EXPERIMENTAL SECTION}

Synthesis. Samples with target compositions $\mathrm{Sr}_{2} \mathrm{MnO}_{2} \mathrm{Cu}_{2} \mathrm{Te}_{2}$ and $\mathrm{Sr}_{2} \mathrm{CoO}_{2} \mathrm{Cu}_{2} \mathrm{Te}_{2}$ (i.e., the compositions with fully occupied $\mathrm{Cu}$ sites were targeted) were synthesized on a 3-4 g scale using a solid-state synthesis route: $\mathrm{SrO}$ (prepared from the thermal decomposition of $\mathrm{SrCO}_{3}$ at $1100{ }^{\circ} \mathrm{C}$, Alfa Aesar, 99.999\%), $M(M=\mathrm{Mn}$ (Aldrich 99+ \%), Co (Alfa Aesar 99.999\%)), Cu (Alfa Aesar 99.999\%), and Te (Alfa Aesar 99.999\%) were ground in the molar ratio 2:1:2:2 before the powder was pelletized under a pressure of $400 \mathrm{MPa}$. The resultant pellet was loaded into an alumina crucible and flame-sealed in an evacuated silica tube. The samples were then heated to a temperature of $750{ }^{\circ} \mathrm{C}$ (ramp rate: $5{ }^{\circ} \mathrm{C} \mathrm{min}{ }^{-1}$ ) for $\sim 48 \mathrm{~h}$ before the tubes were quenched in a bucket of ice/water. Each compound was then subjected to further heat treatments (placed directly into in a furnace at $750{ }^{\circ} \mathrm{C}$ and quenched in ice/water each time) until no further improvement in phase-purity was observed according to laboratory powder X-ray diffraction, this meant each sample was typically heated
2-3 times. At all points during synthesis and storage, the samples were treated as air-sensitive using an argon-filled glovebox (Glovebox Technology Ltd.).

Both oxide telluride products were reacted with a saturated solution of $\mathrm{I}_{2}$ in dry acetonitrile to see if any oxidative deintercalation of $\mathrm{Cu}$ occurred (as judged by changes in lattice parameters). For these reactions, the sample was loaded into a Schlenk flask under an inert atmosphere. $1.5 \mathrm{~mol}$ of $\mathrm{I}_{2}$ per mole of oxide telluride were dissolved in $\sim 30 \mathrm{~cm}^{3}$ of dry acetonitrile $(\mathrm{MeCN})$ in another Schlenk flask. The contents of both flasks were cooled to $0{ }^{\circ} \mathrm{C}$ using a water/ice bath prior to transferring the iodine solution into the flask containing the oxide telluride powder using a cannula. The suspension was stirred for $\sim 2$ days at $0{ }^{\circ} \mathrm{C}$ before filtration and was then thrice washed with clean $\mathrm{MeCN}$. The subambient temperature was used to minimize side reactions.?

Powder Diffraction Measurements. Initial structural characterization was carried out by powder X-ray diffraction (PXRD) on a Bruker D8 Advance Eco instrument (Bragg-Brentano geometry, $\mathrm{Cu}$ $\mathrm{K} \alpha$ radiation). Detailed structural characterization used the highresolution synchrotron X-ray powder diffractometer I11 at the Diamond Light Source, with 0.82 A X-rays calibrated using a silicon standard. ${ }^{12}$ Samples were mixed with either amorphous boron or ground silica glass to minimize absorption and preferred orientation effects and loaded in $0.5 \mathrm{~mm}$ diameter borosilicate capillaries under argon. Low-temperature powder neutron diffraction (PND) measurements to probe changes to the crystal structure as a function of temperature and to characterize magnetic long-range order were performed on the WISH time-of-flight diffractometer at the ISIS Pulsed Neutron Source, U.K. ${ }^{13}$ Here $2-3$ g of sample was loaded under argon into an airtight cylindrical vanadium can sealed with an indium gasket.

Rietveld refinements against PND and PXRD data were conducted using the TOPAS Academic Version 5 software. ${ }^{14}$ Magnetic structures were determined using ISODISTORT ${ }^{15}$ in conjunction with TOPAS Academic. OriginPro $2017^{16}$ was used to model the Warren-like magnetic peak shape of $\mathrm{Sr}_{2} \mathrm{MnO}_{2} \mathrm{Cu}_{1.82(2)} \mathrm{Te}_{2}$.

Magnetometry. Magnetic susceptibilities were measured using a Quantum Design MPMS-XL SQUID magnetometer with 20-60 mg of accurately weighed powder contained in gelatin capsules. Prior to the measurement of the magnetic susceptibility as a function of temperature, the magnetic moment was measured as a function of field at $300 \mathrm{~K}$. Any nonlinearity in the curve was assumed to arise from minuscule amounts of ferromagnetic impurities. $\mathrm{Sr}_{2} \mathrm{CoO}_{2} \mathrm{Cu}_{2} \mathrm{Te}_{2}$ had a nonlinear $M$ versus $H$ curve, and this was assumed to arise from amounts of elemental Co below the detection limit for PXRD. $\mathrm{Sr}_{2} \mathrm{CoO}_{2} \mathrm{Cu}_{2} \mathrm{Te}_{2}$ was therefore measured on warming from $5 \mathrm{~K}$ in two different fields ( 30 and $40 \mathrm{kOe}$ ) above the saturation field of the impurity, and the results of these two measurements at each temperature were subtracted from one another to give the intrinsic magnetic moment of the sample due to the main phase in an "effective $10 \mathrm{kOe}$ " field, which was then used to determine the magnetic susceptibility. This procedure was also adopted in determining the Curie and Weiss constants for the Mn-containing samples, although no significant nonlinearity was observed in the $300 \mathrm{~K} M$ versus $H$ curves for the $\mathrm{Mn}$ compounds, so low magnetic field (100 Oe) measurements were also compared. For these comparative measurements, the samples were measured on warming twice: once when the sample had been cooled in the absence of a field (zero-field-cooled, ZFC) and once when the sample had been cooled in the measuring field (field-cooled, FC). Further investigation of the magnetic behavior of the compounds was performed using magnetization isotherms at various temperatures. For these measurements, the sample was cooled from $300 \mathrm{~K}$ in a $50 \mathrm{kOe}$ field before each measurement of the magnetization of the compound as a function of field in the range $-50 \leq H(\mathrm{kOe}) \leq 50$. 


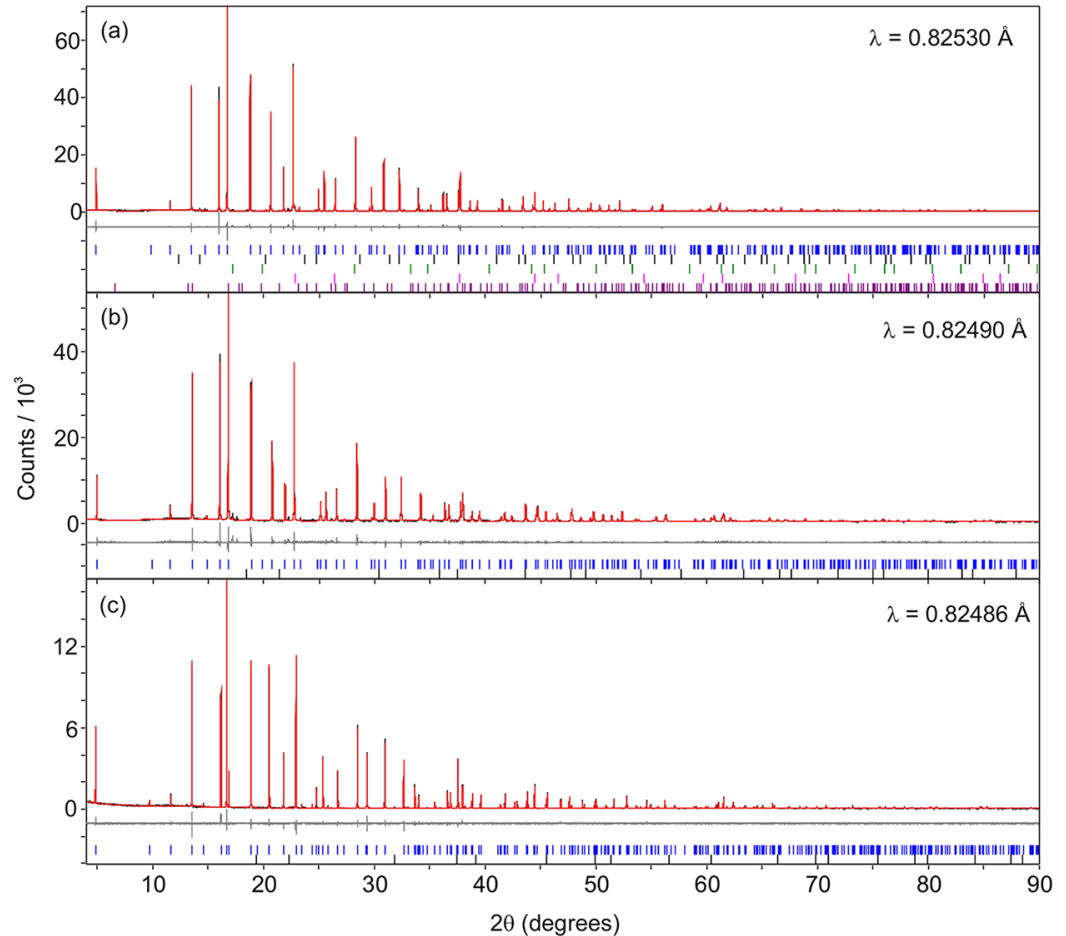

Figure 2. Rietveld plot of (a) parent $\mathrm{Sr}_{2} \mathrm{MnO}_{2} \mathrm{Cu}_{1.82(2)} \mathrm{Te}_{2} ;$ (b) $\mathrm{I}_{2}$-treated $\mathrm{Sr}_{2} \mathrm{MnO}_{2} \mathrm{Cu}_{1.58(2)} \mathrm{Te}_{2}$; and (c) $\mathrm{Sr}_{2} \mathrm{CoO}_{2} \mathrm{Cu}_{2} \mathrm{Te}_{2}$ each measured at room temperature, using the MAC detector on I11. Data (black), fit (red), and difference (gray) are plotted. Tickmarks indicate reflection positions for the main phase (blue, upper set) and small amounts of crystalline impurities, which were additionally identified (in $(\mathrm{a})$ from bottom Cu $\mathrm{Cu}_{2}(1.47 \%$ by mass), $\mathrm{Cu}(1.46 \%), \mathrm{MnO}(0.4 \%), \mathrm{SrTe}(0.6 \%)$; in (b) $\mathrm{MnO}(0.18 \%)$; and in (c) $\mathrm{CoO}(0.65 \%)$ ). Small unindexed peaks in (a) and (b) remain unaccounted for and are presumed to arise from small amounts of a further impurity.

Table 1. Refined Structural Parameters of $\mathrm{Sr}_{2} \mathrm{MnO}_{2} \mathrm{Cu}_{2-x} \mathrm{Te}_{2}$ before and after Oxidation with $\mathrm{I}_{2}$ Solution, Measured Using Synchrotron X-ray and Neutron Powder Diffraction

$\begin{array}{lll}\text { compound } & \mathrm{Sr}_{2} \mathrm{MnO}_{2} \mathrm{Cu}_{1.82(2)} \mathrm{Te}_{2} \text { (as made; before } \mathrm{I}_{2} \text { treatment) } \\ \text { sample number } & \mathrm{JNB303} & \\ \text { radiation } & \mathrm{X} \text {-ray (I11) } & \text { neutron (WISH) } \\ \text { wavelength }(\AA) & 0.82530 & \text { ToF } \\ \text { temp }(\mathrm{K}) & 298 & 100 \\ \text { space group } & I 4 / m m m & \\ a(\AA) & 4.200933(6) & 4.19719(3) \\ c(\AA) & 19.28303(4) & 19.2381(2) \\ c / a & 4.59018(1) & 4.58357(5) \\ \text { vol }\left(\AA^{3}\right) & 340.304(1) & 340.931(1) \\ z(\mathrm{Sr}) & 0.41504(3) & 0.41492(3) \\ z(\mathrm{Te})^{a} & 0.16661(2) & 0.16646(5) \\ o c c(\mathrm{Mn}) & 1.001(3) & 1.003(4) \\ o c c(\mathrm{Cu}) & 0.920(2) & 0.892(2) \\ U_{11}(\mathrm{Sr})\left(\AA^{2}\right) & 0.0153(3) & 0.0045(6) \\ U_{33}(\mathrm{Sr})\left(\AA^{2}\right) & 0.0177(5) & 0.0058(9) \\ U_{\text {iso }}(\mathrm{Mn})\left(\AA^{2}\right) & & 0.0055(7) \\ U_{11}(\mathrm{Mn})\left(\AA^{2}\right) & 0.0119(5) & \\ U_{33}(\mathrm{Mn})\left(\AA^{2}\right) & 0.0234(8) & \\ U_{\text {iso }}(\mathrm{O})\left(\AA^{2}\right) & 0.019(1) & \\ U_{11}(\mathrm{O})\left(\AA^{2}\right) & & 0.010(9) \\ U_{22}(\mathrm{O})\left(\AA^{2}\right) & & 0.012(1) \\ U_{33}(\mathrm{O})\left(\AA^{2}\right) & & 0.002(1) \\ U_{11}(\mathrm{Cu})\left(\AA^{2}\right) & 0.0287(5) & 0.0030(8) \\ U_{33}(\mathrm{Cu})\left(\AA^{2}\right) & 0.0280(7) & 0.014(2) \\ U_{11}(\mathrm{Te})\left(\AA^{2}\right) & 0.0160(3) & 0.0042(5) \\ U_{33}(\mathrm{Te})\left(\AA^{2}\right) & 0.0163(4) & 0.008(1) \\ R_{\text {wp }}(\%) & 8.15 & \end{array}$

$\begin{array}{ll}\mathrm{Sr}_{2} \mathrm{MnO}_{2} \mathrm{Cu}_{1.58(2)} \mathrm{Te}_{2} \text { (after } \mathrm{I}_{2} \text { treatment) } \\ \mathrm{JNB} 409 & \text { neutron (WISH) } \\ \mathrm{X} \text {-ray (I11) } & \mathrm{ToF} \\ 0.82490 & 140 \\ 298 & \\ & 4.16998(4) \\ 4.18093(3) & 19.0582(2) \\ 19.1395(2) & 4.57033(7) \\ 4.57781(5) & 331.373(7) \\ 334.562(5) & 0.41303(4) \\ 0.41323(5) & 0.16661(5) \\ 0.16684(3) & 1.03(1) \\ 0.990(4) & 0.775(2) \\ 0.808(3) & 0.0150(6) \\ 0.0150(3) & 0.007(1) \\ 0.0182(6) & 0.004(1) \\ & \\ 0.0115(5) & \\ 0.022(1) & \\ 0.015(2) & \\ & 0.018(1) \\ & 0.017(1) \\ 0.0297(7) & 0.017(2) \\ 0.0221(9) & 0.009(1) \\ 0.0153(3) & 0.018(2) \\ 0.0175(4) & 0.0085(6) \\ 8.276 & 0.009(1) \\ & 4.57 \\ & \end{array}$

${ }^{a} \mathrm{Sr}, 4 e(0,0, z) ; \mathrm{Mn}, 2 a(0,0,0) ; \mathrm{O}, 4 c(0,1 / 2,0) ; \mathrm{Cu}, 4 d(0,1 / 2,1 / 4) ; \mathrm{Te}, 4 e(0,0, z)$. 


\section{RESULTS AND DISCUSSION}

It was found that samples of both oxide telluride targets with high purity, as judged by laboratory PXRD could be synthesized by conventional high-temperature synthesis.

Crystal Structures and Chemistry. $\mathrm{Sr}_{2} \mathrm{CoO}_{2} \mathrm{Cu}_{2} \mathrm{Te}_{2}$ and $\mathrm{Sr}_{2} \mathrm{MnO}_{2} \mathrm{Cu}_{2} \mathrm{Te}_{2}$ both before and after treatment with $\mathrm{I}_{2}$ were measured on I11. The high quality of the data acquired allowed reliable refinement of the fractional occupancies of each element, as well as confirming the space group, lattice parameters, and atom positions. The Rietveld plots of these refinements are shown in Figure 2, and the refined parameters are shown in Table 1 for the Mn compounds and Table 2 for

Table 2. Refined Parameters of $\mathrm{Sr}_{2} \mathrm{CoO}_{2} \mathrm{Cu}_{2} \mathrm{Te}_{2}$ Measured Using Synchrotron $\mathrm{X}$-ray and Neutron Powder Diffraction

$\begin{array}{lll}\text { compound } & \mathrm{Sr}_{2} \mathrm{CoO}_{2} \mathrm{Cu}_{2} \mathrm{Te}_{2} & \\ \text { sample number } & \mathrm{JNB288} & \\ \text { radiation } & \mathrm{X} \text {-ray (I11) } & \text { neutron (WISH) } \\ \text { wavelength }(\AA) & 0.82486 & \\ \text { temp (K) } & 298 & 300 \\ \text { space group } & I 4 / m m m & \\ a(\AA) & 4.152337(4) & 4.15786(3) \\ c(\AA) & 19.54645(3) & 19.5758(2) \\ c / a & 4.70734(1) & 4.7081(1) \\ \text { vol }\left(\AA^{3}\right) & 337.018(1) & 338.423(6) \\ z(\mathrm{Sr})^{a} & 0.41813(3) & 0.41758(3) \\ z(\mathrm{Te})^{a} & 0.16571(2) & 0.16548(4) \\ o c c(\mathrm{Co}) & 0.992(3) & 0.996(6) \\ o c c(\mathrm{Cu}) & 1.009(2) & 1.000(2) \\ U_{11}(\mathrm{Sr})\left(\AA^{2}\right) & 0.0041(2) & 0.0077(5) \\ U_{33}(\mathrm{Sr})\left(\AA^{2}\right) & 0.0074(3) & 0.0025(8) \\ U_{\text {iso }}(\mathrm{Co})\left(\AA^{2}\right) & & 0.017(1) \\ U_{11}(\mathrm{Co})\left(\AA^{2}\right) & 0.0014(3) & \\ U_{33}(\mathrm{Co})\left(\AA^{2}\right) & 0.012(1) & \\ U_{\text {iso }}(\mathrm{O})\left(\AA^{2}\right) & 0.007(1) & \\ U_{11}(\mathrm{O})\left(\AA^{2}\right) & & 0.012(1) \\ U_{22}(\mathrm{O})\left(\AA^{2}\right) & & 0.011(1) \\ U_{33}(\mathrm{O})\left(\AA^{2}\right) & & 0.006(1) \\ U_{11}(\mathrm{Cu})\left(\AA^{2}\right) & 0.0174(3) & 0.0174(8) \\ U_{33}(\mathrm{Cu})\left(\AA^{2}\right) & 0.0181(5) & 0.027(1) \\ U_{11}(\mathrm{Te})\left(\AA^{2}\right) & 0.0050(1) & 0.011(1) \\ U_{33}(\mathrm{Te})\left(\AA^{2}\right) & 0.0077(2) & 0.023(2) \\ R_{\text {wp }}(\%) & 9.70 & 4.33 \\ 4_{e}(0,0, z) ; & & \end{array}$

${ }^{a} \mathrm{Sr}, 4 e(0,0, z) ; \mathrm{Co}, 2 a(0,0,0) ; \mathrm{O}, 4 c(0,1 / 2,0) ; \mathrm{Cu}, 4 d(0,1 / 2,1 / 4) ; \mathrm{Te}$, $4 e(0,0, z)$.

the Co compounds (see also Table S1 and Figure S2). The PND patterns above the magnetic ordering transitions were also measured in order to assess the phase compositions along with the PXRD measurements. The results are shown in Table 1 (Mn compounds) and Table 2 (Co compound) and in Figures $5 \mathrm{a}$ and $7 \mathrm{a}(\mathrm{Mn})$ and $10 \mathrm{a}(\mathrm{Co})$ for comparison with the low temperature data.

Each of the compounds reported here adopt the same $\mathrm{Sr}_{2} \mathrm{Mn}_{3} \mathrm{Sb}_{2} \mathrm{O}_{2}$ structure type, ${ }^{17}$ crystallizing in space group $I 4 / \mathrm{mmm}$ at room temperature. The crystal structure is shown in Figure 1. Mn and Co are in a highly distended octahedral $\mathrm{MO}_{4} \mathrm{Te}_{2}$ environment, $\mathrm{Cu}$ is in distorted tetrahedral coordination by $\mathrm{Te}$, and $\mathrm{Sr}$ is in an 8 coordinate distorted square antiprismatic $\mathrm{SrO}_{2} \mathrm{Te}_{4}$ environment. Several low intensity peaks in the PXRD pattern of both the "parent" and $\mathrm{I}_{2}$-treated samples of $\mathrm{Sr}_{2} \mathrm{MnO}_{2} \mathrm{Cu}_{2-x} \mathrm{Te}_{2}$ could not be indexed using either any reasonable expansion of the unit cell or with any known impurity. It is assumed these peaks are due to the presence of small quantities $(<2 \mathrm{wt} \%)$ of unknown impurities (see Figure S1).

$\mathrm{Cu}$ Deficiency in $\mathrm{Sr}_{2} \mathrm{MnO}_{2} \mathrm{Cu}_{2-x} \mathrm{Te}_{2}$. It was found from the refinement against both PXRD and PND data (Table 1) that the Mn-containing target phase $\mathrm{Sr}_{2} \mathrm{MnO}_{2} \mathrm{Cu}_{2} \mathrm{Te}_{2}$ is naturally $9(1) \%$ deficient in $\mathrm{Cu}$ when synthesized at high temperatures (the tetrahedral site in the telluride layer was only $91(1) \%$ occupied according to the refinements of the occupancy, and the $1.46 \%$ by mass excess elemental $\mathrm{Cu}$ and a similar mass $\%$ of $\mathrm{Cu}_{2} \mathrm{Te}$ present in the powder pattern are consistent with this level of deficiency in the main oxide telluride phase). The previously reported sulfide and selenide analogues with $\mathrm{Mn}$ in the oxide layers contained significantly larger $\mathrm{Cu}$ deficiencies of about $25 \%{ }^{4}$ This $\mathrm{Cu}$ deficiency increased significantly according to both PXRD and PND refinements (Table 1) when the oxide telluride sample was oxidized with $\mathrm{I}_{2}$, explaining the significant contraction in both lattice parameters $(0.48 \%$ contraction of $a$ and $0.75 \%$ contraction of $c$ on oxidation with excess $\mathrm{I}_{2}$ ). The refined $\mathrm{Cu}$ content obtained using both PXRD and PND refinements decreases on oxidation with $\mathrm{I}_{2}$, while the displacement parameter for $\mathrm{Cu}$ does not change significantly, so we can be confident that the decrease in Cu site occupancy from 91(1)\% $\left(\mathrm{Sr}_{2} \mathrm{MnO}_{2} \mathrm{Cu}_{1.82(2)} \mathrm{Te}_{2}\right)$ in the as-made sample to $79(1) \%$ $\left(\mathrm{Sr}_{2} \mathrm{MnO}_{2} \mathrm{Cu}_{1.58(2)} \mathrm{Te}_{2}\right)$ in the iodine-oxidized product is real and we use the mean values obtained in the two refinements (Table 1) to describe the compositions. There was no discernible deficiency observed on the Mn site according to the refinements.

Comparison of the room temperature structural parameters of the $\mathrm{Sr}_{2} \mathrm{MnO}_{2} \mathrm{Cu}_{2-x} \mathrm{Te}_{2}$ phases (obtained from PXRD data) with the sulfide and selenide analogues (Table 3 ) shows that substituting Se by $\mathrm{Te}$ causes a significantly larger increase in both $a$ and $c$ than the substitution of S by Se. This may be rationalized by considering that $S$ (radius $1.84 \AA$ ) and $\mathrm{Se}$ (radius $1.98 \AA$ ) are fairly similar in size due to the $3 d$ contraction while Te (radius $2.21 \AA$ ) is much larger. ${ }^{18}$ As the lattice parameter $a$ equals twice the $\mathrm{Mn}-\mathrm{O}$ distance and is significantly larger in $\mathrm{Sr}_{2} \mathrm{MnO}_{2} \mathrm{Cu}_{1.82(2)} \mathrm{Te}_{2}$ than in the sulfide or selenide analogues, this increase in the $\mathrm{Mn}-\mathrm{O}$ distance is likely a significant factor in the stabilization of a significantly lower $\mathrm{Mn}$ oxidation state of $+2.18(2)$ in the oxide telluride $\mathrm{Sr}_{2} \mathrm{MnO}_{2} \mathrm{Cu}_{1.82(2)} \mathrm{Te}_{2}$ synthesized at high temperatures in the presence of excess $\mathrm{Cu}$ compared with the $\mathrm{Mn}$ oxidation state of +2.5 in the sulfide and selenide analogues synthesized under similar conditions. The increase in the chalcogenide ion radius is best accommodated in this layered crystal structure by an increase in the $c / a$ ratio, and this causes the $\mathrm{Ch}-\mathrm{Cu}-\mathrm{Ch}$ bond angles to deviate from the ideal tetrahedral angle $\left(109.5^{\circ}\right)$ as the tetrahedra become compressed in the basal $(a b)$ plane. Note that the $\mathrm{MnO}_{4} \mathrm{Ch}_{2}$ octahedron is highly distended, with relatively long $\mathrm{Mn}-\mathrm{Ch}$ distances, indicating a rather weak interaction of the metal with these ligands and a highly anisotropic ligand field.

$\mathrm{Sr}_{2} \mathrm{CoO}_{2} \mathrm{Cu}_{2} \mathrm{Te}_{2}$. In contrast with the $\mathrm{Mn}$ analogue, the $\mathrm{Cu}$ site of $\mathrm{Sr}_{2} \mathrm{CoO}_{2} \mathrm{Cu}_{2} \mathrm{Te}_{2}$ was found to be fully occupied within the uncertainties intrinsic to the PXRD and PND refinements, and this compound was also found to be inert to oxidation by $\mathrm{I}_{2}$, as shown by the comparison of the lattice parameters of the compound before and after reaction with $\mathrm{I}_{2}$ in Table S2 and Figure S3 in the Supporting Information. This is consistent 
Table 3. Comparison of Selected Parameters (Room Temperature) of Several Mn-Containing Oxide Chalcogenides

\begin{tabular}{|c|c|c|c|c|}
\hline compound & $\mathrm{Sr}_{2} \mathrm{MnO}_{2} \mathrm{Cu}_{1.5} \mathrm{~S}_{2}$ & $\mathrm{Sr}_{2} \mathrm{MnO}_{2} \mathrm{Cu}_{1.54} \mathrm{Se}_{2}$ & parent $\mathrm{Sr}_{2} \mathrm{MnO}_{2} \mathrm{Cu}_{1.82(2)} \mathrm{Te}_{2}$ & $\mathrm{I}_{2}$-treated $\mathrm{Sr}_{2} \mathrm{MnO}_{2} \mathrm{Cu}_{1.58(2)} \mathrm{Te}_{2}$ \\
\hline reference & 4 & 4 & this work & this work \\
\hline$a(\AA)$ & $4.01216(3)$ & $4.06655(3)$ & $4.200933(6)$ & $4.18093(3)$ \\
\hline$c(\AA)$ & $17.1915(2)$ & $17.8830(1)$ & $19.28303(4)$ & $19.1395(2)$ \\
\hline$c / a$ & $4.28485(6)$ & $4.39759(4)$ & $4.59018(1)$ & $4.57781(5)$ \\
\hline $\operatorname{vol}\left(\AA^{3}\right)$ & $276.739(6)$ & $295.729(5)$ & $340.304(1)$ & $334.562(5)$ \\
\hline $\mathrm{Cu}$ occupancy & $0.745(5)$ & $0.773(2)$ & $0.91(1)^{c}$ & $0.79(1)^{c}$ \\
\hline $\mathrm{Mn}-\mathrm{O}[4]^{a}(\AA)$ & $2.00608(5)$ & $2.03328(1)$ & $2.10047(4)$ & $2.09047(2)$ \\
\hline $\mathrm{Mn}-\mathrm{Ch}[2](\AA)$ & $2.9200(9)$ & $3.0002(3)$ & $3.2128(4)$ & $3.1932(5)$ \\
\hline $\mathrm{Mn}-\mathrm{Ch} / \mathrm{Mn}-\mathrm{O}$ & $1.4556(4)$ & $1.4779(5)$ & $1.5296(2)$ & $1.5275(3)$ \\
\hline $\mathrm{Cu}-\mathrm{Ch}[4](\AA)$ & $2.4337(1)$ & $2.5094(2)$ & $2.6453(2)$ & $2.6274(3)$ \\
\hline $\mathrm{Ch}-\mathrm{Cu}-\mathrm{Ch}, \alpha^{b}\left(^{\circ}\right)[2]$ & $111.03(3)$ & $108.25(5)$ & $105.13(1)$ & $105.43(2)$ \\
\hline $\mathrm{Ch}-\mathrm{Cu}-\mathrm{Ch}, \beta^{b}\left(^{\circ}\right)[4]$ & $108.70(2)$ & $110.09(5)$ & $111.685(7)$ & $111.53(1)$ \\
\hline
\end{tabular}

${ }^{a}$ Multiplicity in square brackets. ${ }^{b}$ See Figure S16 in the Supporting Information for definition of angle. ${ }^{c}$ Mean of values from PXRD and PND refinements in Table 1.

with the less facile stabilization of Co oxidation states above +2 compared with $\mathrm{Mn}^{11}$ There was also no evidence for a deficiency of $\mathrm{Co}$ in this compound.

$\mathrm{Sr}_{2} \mathrm{CoO}_{2} \mathrm{Cu}_{2} \mathrm{Te}_{2}$ can also be compared with its sulfide and selenide analogues (see Table 4 and Figure 3). A similar

Table 4. Comparison of Selected Parameters of Several CoContaining Oxide Chalcogenides

$\begin{array}{llll}\text { compound } & \mathrm{Sr}_{2} \mathrm{CoO}_{2} \mathrm{Cu}_{2} \mathrm{~S}_{2} & \mathrm{Sr}_{2} \mathrm{CoO}_{2} \mathrm{Cu}_{2} \mathrm{Se}_{2} & \begin{array}{l}\mathrm{Sr}_{2} \mathrm{CoO}_{2} \mathrm{Cu}_{2} \mathrm{Te}_{2} \\ \text { this work }\end{array} \\ \begin{array}{l}\text { ref } \\ \text { th) }\end{array} & 19 & 4.152337(4) \\ c(\AA) & 17.71555(9) & 18.360(1) & 19.54645(3) \\ c / a & 4.43855(3) & 4.5279(3) & 4.70734(1) \\ \operatorname{vol}\left(\AA^{3}\right) & 282.216(3) & 301.88(3) & 337.018(1) \\ \mathrm{Co}-\mathrm{O}[4]^{a}(\AA) & 1.99565(1) & 2.0275(1) & 2.07617(1) \\ \mathrm{Co}-\mathrm{Ch}[2](\AA) & 3.0327(5) & 3.079(4) & 3.2390(4) \\ \mathrm{Co}-\mathrm{Ch} / \mathrm{Co}-\mathrm{O} & 1.5197(3) & 1.519(2) & 1.5601(2) \\ \mathrm{Cu}-\mathrm{Ch}[4](\AA) & 2.4356(3) & 2.529(3) & 2.6511(3) \\ \mathrm{Ch}-\mathrm{Cu}-\mathrm{Ch}, & 109.185(10) & 110.92(7) & 103.132(12) \\ \alpha^{b}\left({ }^{\circ}\right)[2] & & & \\ \mathrm{Ch}-\mathrm{Cu}-\mathrm{Ch}, & 110.04(2) & 106.61(14) & 112.731(6) \\ \beta^{b}\left({ }^{\circ}\right)[4] & & & \end{array}$

${ }^{a}$ Multiplicity in square brackets. ${ }^{b}$ See Figure S16 in the Supporting Information for definition of angle.

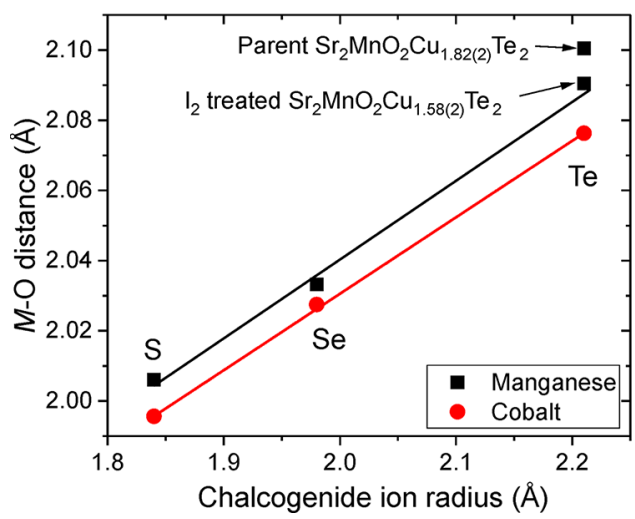

Figure 3. Relationship between the radius of the chalcogenide ion (ref 18 ) and the $M-O$ distance. Since the $M-O$ distance equals half the $a$ lattice parameter, the uncertainty is smaller than the size of the symbols. Lines are guides to the eye.

increase in the $M-\mathrm{O}$ bond distance is observed on the substitution of Se for $\mathrm{Te}$ as in the case of the manganese analogues. Figure 3 demonstrates that there is an approximately linear relationship between the size of the chalcogenide ion and the increase in the $\mathrm{M}-\mathrm{O}$ bond distance in both the Co and $\mathrm{Mn}$ analogues for a constant transition metal oxidation state $(+2$ for Co and $\sim+2.5$ for $\mathrm{Mn})$. However, the $\mathrm{Mn}-\mathrm{O}$ distance of the "parent" $\mathrm{Sr}_{2} \mathrm{MnO}_{2} \mathrm{Cu}_{1.82(2)} \mathrm{Te}_{2}$ phase synthesized at high temperatures is marginally larger than might be expected from the increase in the chalcogenide ion size. This can be attributed to the lower $\mathrm{Mn}$ oxidation state in $\mathrm{Sr}_{2} \mathrm{MnO}_{2} \mathrm{Cu}_{1.82(2)} \mathrm{Te}_{2}(+2.18(2))$ compared with the much more similar oxidation states for the sulfide and selenide equivalents and for the oxidized telluride $(+2.42(2))$. As discussed above, in the context of the manganese analogue, the large telluride ion distorts the chalcogenide layers significantly away from the ideal tetrahedral angle in the cobalt analogue. ${ }^{6,19}$

Magnetic Properties. Magnetic Ordering in $\mathrm{Sr}_{2} \mathrm{MnO}_{2} \mathrm{Cu}_{2-x} \mathrm{Te}_{2}$ Phases. The magnetic susceptibility measurements of the "parent" $\mathrm{Sr}_{2} \mathrm{MnO}_{2} \mathrm{Cu}_{1.82(2)} \mathrm{Te}_{2}$ phase synthesized at high temperatures show that the $\mathrm{ZFC}$ and $\mathrm{FC}$ curves diverge below $\sim 41 \mathrm{~K}$ (Figure $4 \mathrm{a}$ ), with behavior that resembles that of a spin-glass-freezing. There is also a broad hump in the susceptibility located at $\sim 70 \mathrm{~K}$. By contrast, the magnetic susceptibility of the $\mathrm{I}_{2}$-treated sample $\mathrm{Sr}_{2} \mathrm{MnO}_{2} \mathrm{Cu}_{1.58(2)} \mathrm{Te}_{2}$ shows a clear cusp at $78(1) \mathrm{K}$, indicative of antiferromagnetic ordering. The divergence of the $\mathrm{ZFC} / \mathrm{FC}$ curves below $\sim 20 \mathrm{~K}$ suggests that there is also a glassy component to the magnetism in the oxidized sample. The $150 \mathrm{~K}$ (i.e., above any magnetic ordering transitions) magnetization isotherms of the two phases are linear and pass through the origin with no apparent hysteresis (Figures $\mathrm{S} 7$ and $\mathrm{S} 8$ ), but at $5 \mathrm{~K}$ the isotherm of the $\mathrm{Sr}_{2} \mathrm{MnO}_{2} \mathrm{Cu}_{1.82(2)} \mathrm{Te}_{2}$ phase shows a significant curvature, and a measurable displacement from the origin, and in both samples a hysteresis is evident at low fields, consistent with the apparent glassy behavior. This glassy behavior, and the possibility that it could arise from an impurity, would require further analysis beyond the scope of this article (see Supporting Information).

The $\mu_{\text {eff }}$ for $\mathrm{Sr}_{2} \mathrm{MnO}_{2} \mathrm{Cu}_{1.82(2)} \mathrm{Te}_{2}$ (5.67(1) $\mu_{\mathrm{B}}$; Table 5) obtained from a Curie-Weiss fit (Figure S9) compares closely to the calculated spin-only magnetic moment expected for a mean $\mathrm{Mn}$ oxidation state of $+2.18\left(\mu_{\text {spin-only }}=5.71 \mu_{\mathrm{B}}\right)$. The Weiss temperature is positive, suggesting net ferromagnetic interactions and has a magnitude of $70(1) \mathrm{K}$, well below the temperatures used for the analysis, suggesting that the CurieWeiss treatment is valid in this case. The values extracted from 

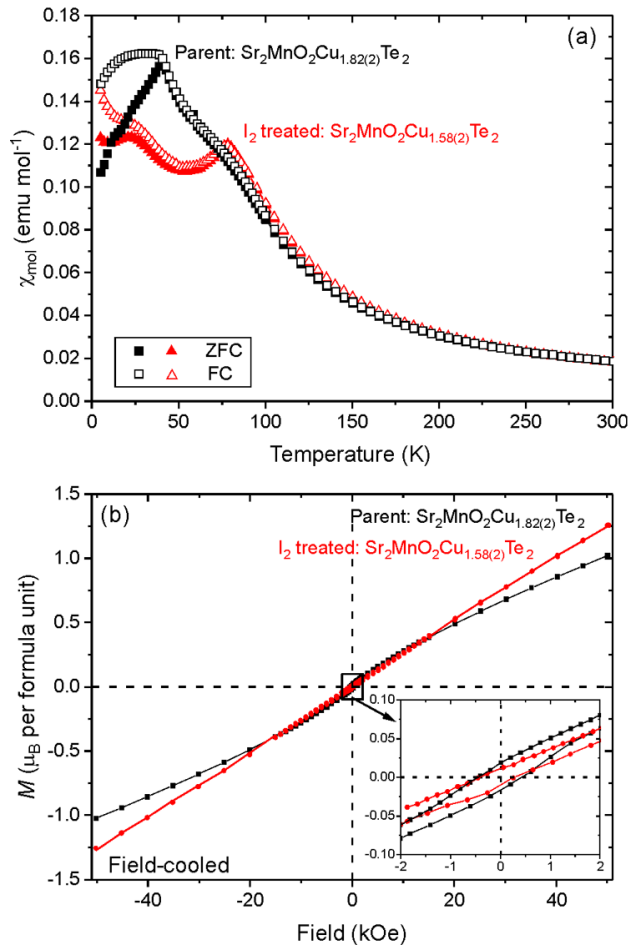

Figure 4. (a) ZFC and FC magnetic susceptibility curves of as-made and $\mathrm{I}_{2}$-treated $\mathrm{Sr}_{2} \mathrm{MnO}_{2} \mathrm{Cu}_{2-x} \mathrm{Te}_{2}$, measured at a field of 100 Oe. (b) Field-cooled (in $50 \mathrm{kOe}$ ) magnetization isotherms of as-made and $\mathrm{I}_{2}$ treated $\mathrm{Sr}_{2} \mathrm{MnO}_{2} \mathrm{Cu}_{2-x} \mathrm{Te}_{2}$, measured at $5 \mathrm{~K}$. The inset emphasizes the low field region. See also Figure S7.

Table 5. Results of Curie-Weiss Fits for

$\mathrm{Sr}_{2} \mathrm{MnO}_{2} \mathrm{Cu}_{1.82(2)} \mathrm{Te}_{2}$ and $\mathrm{Sr}_{2} \mathrm{MnO}_{2} \mathrm{Cu}_{1.58(2)} \mathrm{Te}_{2}$

$\begin{array}{lll}\text { compound } & \begin{array}{l}\text { parent } \\ \mathrm{Sr}_{2} \mathrm{MnO}_{2} \mathrm{Cu}_{1.82(2)} \mathrm{Te}_{2}\end{array} & \begin{array}{l}\mathrm{I}_{2} \text {-treated } \\ \mathrm{Sr}_{2} \mathrm{MnO}_{2} \mathrm{Cu}_{1.58(2)} \mathrm{Te}_{2}\end{array} \\ \text { Curie constant } & 4.016(7) & 4.03(2) \\ \text { Weiss temp (K) } & 70(1) & 69(1) \\ \mu_{\text {eff }}\left(\mu_{\mathrm{B}}\right) & 5.67(1) & 5.68(2)\end{array}$

the magnetic susceptibility of the $\mathrm{I}_{2}$-treated sample are similar within the uncertainty, reflecting that only a low level of oxidation has occurred (for the level of $\mathrm{Mn}$ oxidation (from $\mathrm{Mn}^{2.18(2)+}$ to $\mathrm{Mn}^{2.42(2)+}$ ) one would expect a decrease of just $3.5 \%$ in the size of the spin-only effective magnetic moment).

Low-temperature PND at 1.7 and $100 \mathrm{~K}$ was used to probe magnetic ordering in $\mathrm{Sr}_{2} \mathrm{MnO}_{2} \mathrm{Cu}_{1.82(2)} \mathrm{Te}_{2}$. Figure 5 shows that all the peaks in the pattern at $100 \mathrm{~K}$ could be indexed by the ambient temperature structure of $\mathrm{Sr}_{2} \mathrm{MnO}_{2} \mathrm{Cu}_{1.82(2)} \mathrm{Te}_{2}$ and known impurities, ${ }^{20}$ with no additional intensity suggesting that there is no low-temperature ordering of the relatively low concentration $(9(1) \%)$ of $\mathrm{Cu}$ vacancies. At $1.7 \mathrm{~K}$, additional asymmetric features were observed, the most intense being a peak at $d=5.9 \AA$; these were assumed to be magnetic in origin.

This peak at $5.9 \AA$ was indexed as the 100 peak of a $\sqrt{2} a \times$ $\sqrt{2} a \times c$ expansion of the nuclear unit cell. The peak, with a long "tail" at low $d$-spacing, has a shape corresponding to the Warren function ${ }^{21}$ which was first used to describe the PXRD pattern of two-dimensional carbon black, a sample which was well ordered in the $a b$-plane, but disordered in the $c$ direction. $^{21,22}$ This peak-shape has been found to be a good descriptor for the magnetic peaks in a number of compounds including the structurally related $\mathrm{Sr}_{2} \mathrm{MnO}_{2} \mathrm{Mn}_{2} \mathrm{As}_{2}{ }^{23}$

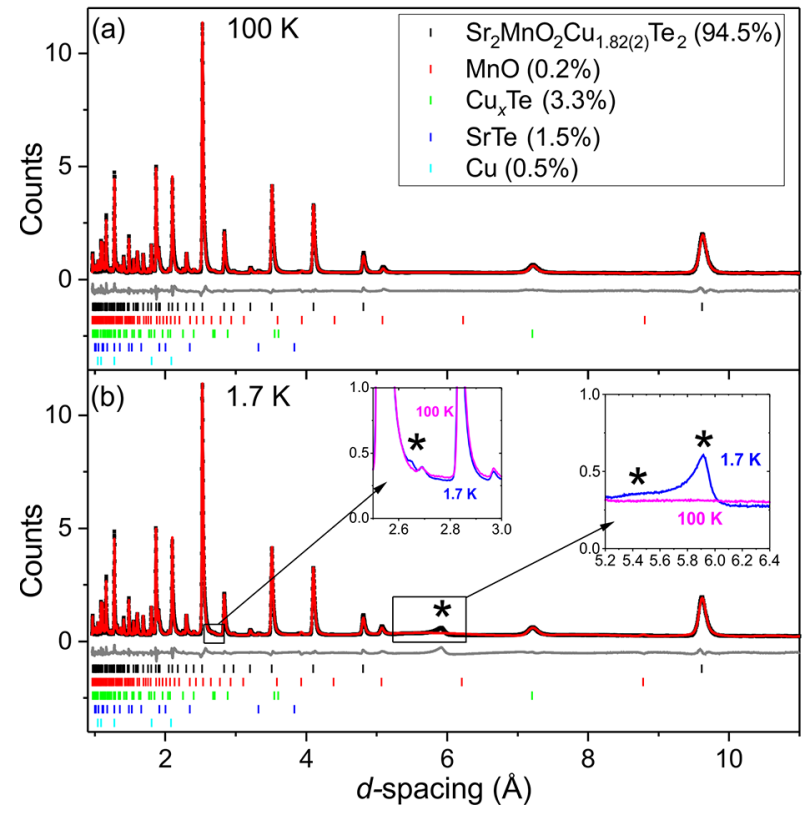

Figure 5. Rietveld fit to the WISH $2 / 9$ bank $\left(2 \theta=58.3^{\circ}\right)$ data of $\mathrm{Sr}_{2} \mathrm{MnO}_{2} \mathrm{Cu}_{1.82(2)} \mathrm{Te}_{2}$ at (a) $100 \mathrm{~K}$ and (b) $1.7 \mathrm{~K}$. The $*$ symbols emphasize the peaks that appear on cooling and cannot be indexed using the nuclear model.

$\mathrm{La}_{2} \mathrm{O}_{2} \mathrm{Fe}_{2} \mathrm{OSe}_{2}{ }^{24}$ and $\mathrm{Sr}_{2} \mathrm{~F}_{2} \mathrm{Fe}_{2} \mathrm{OS}_{2}{ }^{25}$ The development of a Warren-like peak shows that the magnetic ordering is twodimensional and short-range in nature. To model the peak as Warren-like the data was converted to $Q(2 \pi / d)$ and the peak fitted (Figure 6) using the function shown in the Supporting

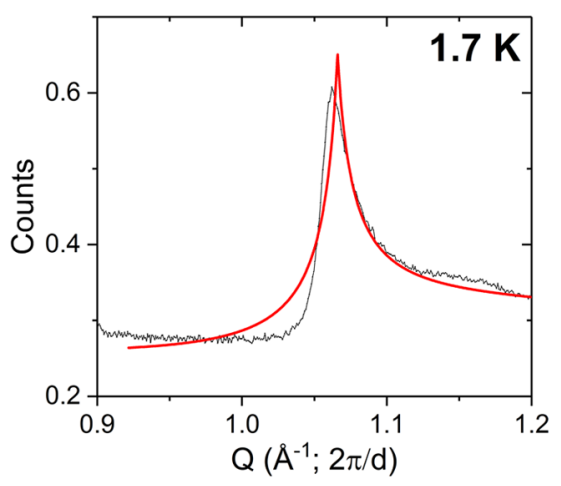

Figure 6. Fit to the peak at $Q \sim 1.07 \AA^{-1}$ when a Warren-like peakshape function is used. The data is from the measurement of parent $\mathrm{Sr}_{2} \mathrm{MnO}_{2} \mathrm{Cu}_{1.82(2)} \mathrm{Te}_{2}$ at $1.7 \mathrm{~K}$ using the $2 / 9$ bank of WISH $(2 \theta=$ $\left.58.3^{\circ}\right)$.

Information. ${ }^{21,25}$ This gave a reasonable qualitative fit to the shape of the peak, fitting the high- $Q$ asymmetry particularly well, and producing a correlation length of 93(6) $\AA$.

While a detailed analysis of the temperature dependence of this magnetic peak was not possible due to lack of neutron beam time, a measurement at $55 \mathrm{~K}$ showed that it still had significant intensity (Figure S10 in the Supporting Information), but was clearly absent at $100 \mathrm{~K}$, suggesting that the appearance of the magnetic peak is associated with the feature in the magnetic susceptibility curve at $\sim 70 \mathrm{~K}$.

A $3 \mathrm{~g}$ sample of $\mathrm{Sr}_{2} \mathrm{MnO}_{2} \mathrm{Cu}_{1.58(2)} \mathrm{Te}_{2}$ (i.e., the product after $\mathrm{I}_{2}$ oxidation) was also measured using $\mathrm{PND}$ at $1.7,50$, and 140 
$\mathrm{K}$. Despite the larger concentration of vacancies on the $\mathrm{Cu}$ sites than in the parent phase, there was no evidence for $\mathrm{Cu}$ / vacancy ordering from the diffraction pattern (similar to the selenide analogue, but in contrast to the sulfide analogue ${ }^{4}$ ) because, although new reflections appeared in the diffraction pattern at $1.7 \mathrm{~K}$ that were not observed at $140 \mathrm{~K}$ (Figure 7 ),

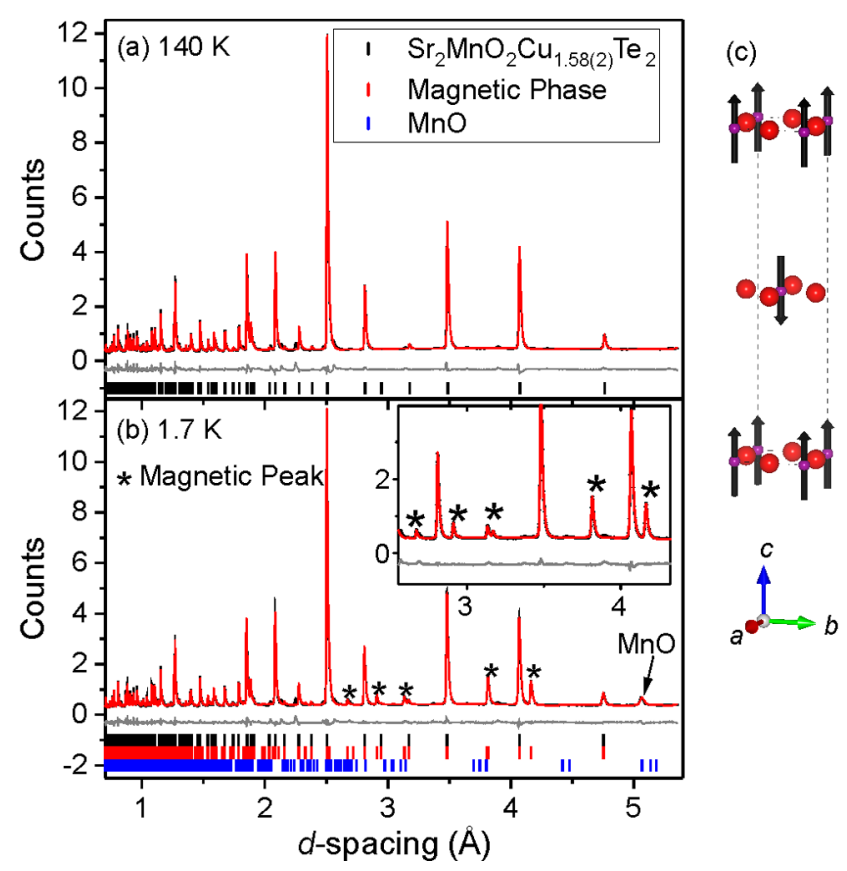

Figure 7. Rietveld plot of $\mathrm{I}_{2}$-treated $\mathrm{Sr}_{2} \mathrm{MnO}_{2} \mathrm{Cu}_{1.58(2)} \mathrm{Te}_{2}$ at (a) $140 \mathrm{~K}$ and (b) $1.7 \mathrm{~K}$ using the $4 / 7\left(121.7^{\circ}\right)$ bank of WISH. The * symbols highlight the peaks attributed to long-range magnetic ordering. The labeled arrow indicates the single dominant reflection that arises from the magnetic ordering of $\mathrm{MnO}^{20}(<1 \mathrm{wt} \%$ impurity in this sample and only evident in the PND measurement through the intense magnetic peak at $d=5.1 \AA$ ). (c) Magnetic model used to account for the magnetic intensity; for clarity, only the manganese atoms (small magenta circles) and the oxygen atoms (large red atoms) are shown.

these were restricted to long $d$-spacings, suggesting that they were magnetic in origin. These new reflections were indexed using the nuclear cell dimensions, but with loss of body centring. Symmetry mode analysis in magnetic space group $P 1$ (1.1), revealed that just the $\mathrm{mM}^{+}(\mathrm{a})$ mode was required which corresponds to A-type magnetic ordering with magnetic moments ferromagnetically aligned within the $a b$-plane, but antiferromagnetically aligned between the planes (Figure $7 \mathrm{c}$ ). The magnetic moment lies parallel to the $c$-axis. The space group $P_{I} 4 / m n c$ (128.410 in the Belov, Neronova, and Smirnova (BNS) scheme, ${ }^{26,27}$ which corresponds to $I_{P} 4 /$ $\mathrm{mm}^{\prime} \mathrm{m}^{\prime}$ (139.15.1193) in the Opechowski and Guccione (OG) scheme, ${ }^{28}$ was found to be the highest symmetry magnetic space group that could accommodate this symmetry mode. The fit (Figure $7 \mathrm{~b}$ and Table 6) produced a refined long-rangeordered magnetic moment of $3.07(4) \mu_{\mathrm{B}}$ per $\mathrm{Mn}$ ion at $1.7 \mathrm{~K}$.

The powder neutron diffraction pattern measured at $50 \mathrm{~K}$ shows that the magnetic peaks are still of significant intensity (Figure S11 in the Supporting Information), which correlates with the antiferromagnetic long-range ordering temperature corresponding to the cusp in the magnetic susceptibility at $\sim 70$ $\mathrm{K}$.
Table 6. Refined Parameters for the Magnetic Ordering of $\mathrm{Sr}_{2} \mathrm{MnO}_{2} \mathrm{Cu}_{1.58(2)} \mathrm{Te}_{2}$ at $1.7 \mathrm{~K}$

$\begin{array}{ll}\text { radiation } & \text { neutron, ToF } \\ \text { diffractometer } & \text { WISH } \\ \text { temp }(\mathrm{K}) & 1.7 \\ \text { magnetic space group (BNS scheme) } & P_{1} 4 / m n c(128.410) \\ \mu_{\mathrm{c}}\left(\mu_{\mathrm{B}}\right) & 3.07(4) \\ R_{\text {wp }}(\%) & 4.656\end{array}$

As described above, the largest observed magnetic peak in the parent phase $\mathrm{Sr}_{2} \mathrm{MnO}_{2} \mathrm{Cu}_{1.82(2)} \mathrm{Te}_{2}$ was fitted using a Warren-like function and indexed using a $\sqrt{2 a} \times \sqrt{2} a$ expansion of the unit cell. This suggests a model in which the primary magnetic interaction is the antiferromagnetic interaction of nearest-neighbor $\mathrm{Mn}$ ions, but that the presence of $18(2) \% \mathrm{Mn}^{3+}$ ions (from average oxidation state $\mathrm{Mn}^{2.18(2)+}$ ) frustrates the antiferromagnetic ordering, causing spin disorder, and indeed resulting in complete disorder in the out-of-plane direction, hence the lack of Bragg peaks resulting from magnetic long-range order, even at $1.7 \mathrm{~K}$. If the decrease in the $\mathrm{Cu}$ occupancy during oxidation with $\mathrm{I}_{2}$ is assumed to result solely in oxidation of the $\mathrm{Mn}$ ions, then this implies the oxidation state increases to $\mathrm{Mn}^{2.42(2)+}$ for the refined composition of $\mathrm{Sr}_{2} \mathrm{MnO}_{2} \mathrm{Cu}_{1.58(2)} \mathrm{Te}_{2}$. As noted above, the $\mathrm{Mn}$ ion is in a highly anisotropic ligand field, effectively in square planar coordination by oxide, with rather weak interactions with the chalcogenide, so the $d_{x 2-y 2}$ orbital lies high in energy and is the Mn orbital, which dominates the interaction between $\mathrm{Mn}$ ions via $\sigma$-type interactions with the intervening oxide ions. $\mathrm{Mn}^{2+}\left(d^{5}\right)$ and $\mathrm{Mn}^{3+}\left(d^{4}\right)$ ions have half-occupied or empty $d_{x 2-y 2}$ orbitals, respectively, so ferromagnetic $180^{\circ}$ superexchange between $\mathrm{Mn}^{2+}\left(d^{5}\right)$ and $\mathrm{Mn}^{3+}\left(d^{4}\right)$ ions is possible, leading to ferromagnetic planes in an A-type magnetic structure with $\mathrm{Mn}^{2+} / \mathrm{Mn}^{3+}$ charge order. At the other extreme, itinerant $d_{x 2-y 2}$ electrons (i.e., no charge order) would also promote such ferromagnetic planes. Experimentally the A-type antiferromagnetic structure with ferromagnetic $\mathrm{MnO}_{2}$ planes coupled antiferromagnetically is observed in the selenide analogues $\mathrm{Sr}_{2} \mathrm{MnO}_{2} \mathrm{Cu}_{1.5} \mathrm{Se}_{2}$ and $\mathrm{Sr}_{2} \mathrm{MnO}_{2} \mathrm{Ag}_{1.5} \mathrm{Se}_{2}$, ${ }^{4,9}$ in oxide sulfide analogues with thicker copper sulfide layers, ${ }^{29}$ and in numerous mixed-valent $\mathrm{Mn}^{3+/ 4+}$ oxide manganites. ${ }^{30}$ Table 7 compares the magnetic behavior of the sulfide and selenide analogues of $\mathrm{Sr}_{2} \mathrm{MnO}_{2} \mathrm{Cu}_{1.58(2)} \mathrm{Te}_{2}$. The long-range ordered moment of $\mathrm{Sr}_{2} \mathrm{MnO}_{2} \mathrm{Cu}_{1.58(2)} \mathrm{Te}_{2}$ is significantly smaller than those of the other analogues. $\mathrm{Sr}_{2} \mathrm{MnO}_{2} \mathrm{Cu}_{1.58(2)} \mathrm{Te}_{2}$ has average oxidation state $\mathrm{Mn}^{2.42(2)+}$, suggesting a $42(2): 58(2)$ ratio of $\mathrm{Mn}^{3+} / \mathrm{Mn}^{2+}$ ions, so the number of $d$-electrons per $\mathrm{Mn}$ is slightly larger in the oxide telluride. However, if there is charge order in the $\mathrm{MnO}_{2}$ sheet, the departure from the 50:50 ratio of $\mathrm{Mn}^{3+} / \mathrm{Mn}^{2+}$ ions means that this ordering will not be perfect, so not every $\mathrm{Mn}-\mathrm{O}-\mathrm{Mn}$ superexchange interaction will involve a $\mathrm{Mn}^{2+}$ and a $\mathrm{Mn}^{3+}$ ion, causing frustration in the magnetic ordering and therefore reducing the overall long-range ordered moment. Such disorder is known to reduce the ordered moment in Co analogues. ${ }^{5}$ We note, however, that in these layered mixedvalent $\mathrm{Mn}^{2+/ 3+}$ oxide chalcogenides, there is no clear signature of charge ordering of the oxidation states from diffraction measurements, aside from elongation of the low temperature oxide ellipsoids in $\mathrm{Sr}_{2} \mathrm{MnO}_{2} \mathrm{Cu}_{1.5} \mathrm{~S}_{2}{ }^{4}$ Further work is required to probe further the competition between these different magnetic ground states in these compounds and their 
Table 7. Comparison of Selected Magnetic Parameters of the Manganese-Containing Oxide Chalcogenides

\begin{tabular}{|c|c|c|c|c|}
\hline compound & $\mathrm{Sr}_{2} \mathrm{MnO}_{2} \mathrm{Cu}_{1.5} \mathrm{~S}_{2}$ & $\mathrm{Sr}_{2} \mathrm{MnO}_{2} \mathrm{Cu}_{1.5} \mathrm{Se}_{2}$ & $\mathrm{Sr}_{2} \mathrm{MnO}_{2} \mathrm{Ag}_{1.5} \mathrm{Se}_{2}$ & $\mathrm{Sr}_{2} \mathrm{MnO}_{2} \mathrm{Cu}_{1.58(2)} \mathrm{Te}_{2}\left(\mathrm{I}_{2}\right.$-treated $)$ \\
\hline ref & 4 & 4 & 9 & this work \\
\hline Néel temp, $T_{N}(K)$ & 29 & 53 & $63(1)$ & $78(1)$ \\
\hline Weiss temp $(\mathrm{K})$ & $17(1)$ & $43(1)$ & $45(3)$ & $69(1)$ \\
\hline effective moment, $\mu_{\text {eff }}\left(\mu_{\mathrm{B}}\right)$ & $5.3(1)$ & $5.4(1)$ & $5.45(1)$ & $5.68(2)$ \\
\hline magnetic structure & CE-type & A-type & A-type & A-type \\
\hline ordered moment $\left(\mu_{\mathrm{B}}\right)$ & $4.0(1)$ & $4.1(1)$ & $3.99(2)$ & $3.07(4)$ \\
\hline
\end{tabular}

relationship to crystal structures and possible charge-ordering phenomena within the $\mathrm{MnO}_{2}$ planes, and the relationship with the mixed-valent $\left(\mathrm{Mn}^{3+/ 4+}\right)$ manganite oxides.

Both $T_{\mathrm{N}}$ and the Weiss temperature increase with the size of the chalcogenide and coinage-metal ions in this series and, therefore, with the interlayer spacing. This is a somewhat surprising observation, but is possibly related to the strength of the covalent interaction between $\mathrm{Mn}$ and the chalcogenide ions which will determine the strength of interplane exchange interactions. In Figure 8, the radius of the chalcogenide ion,

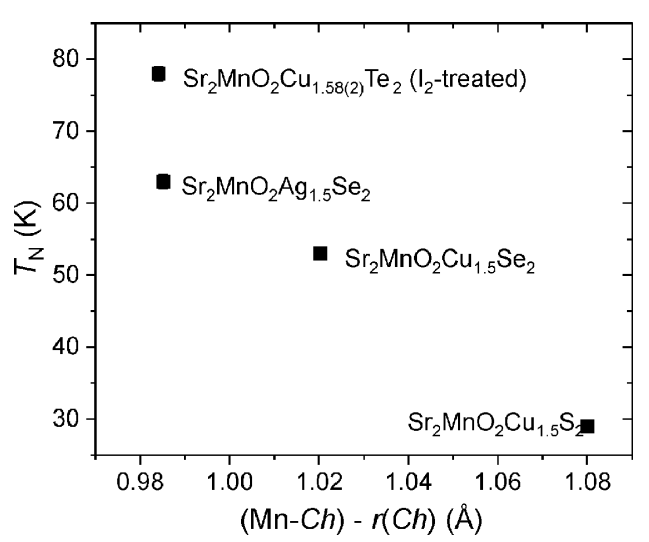

Figure 8. Néel temperature $\left(T_{\mathrm{N}}\right)$ of manganese-containing oxychalcogenides against the difference between the $\mathrm{Mn}-\mathrm{Ch}$ distance and the chalcogenide ionic radius, obtained from values in ref 18 .

$r(\mathrm{Ch})^{18}$ has been subtracted from the $\mathrm{Mn}-\mathrm{Ch}$ distance $d(\mathrm{Mn}-\mathrm{Ch})$ to obtain a parameter inversely related to the degree of $\mathrm{Mn}-\mathrm{Ch}$ covalency and the value plotted against the measured temperature of long-range magnetic ordering. There is a strong correlation between a larger $T_{\mathrm{N}}$ and a smaller value of $d(\mathrm{Mn}-\mathrm{Ch})-r(\mathrm{Ch})$, suggesting that greater $\mathrm{Mn}-\mathrm{Ch}$ covalency results in a larger $T_{\mathrm{N}}$.

Magnetic Ordering in $\mathrm{Sr}_{2} \mathrm{CoO}_{2} \mathrm{Cu}_{2} \mathrm{Te}_{2}$. The sample of $\mathrm{Sr}_{2} \mathrm{CoO}_{2} \mathrm{Cu}_{2} \mathrm{Te}_{2}$ contained minuscule ferromagnetic impurities (presumed to be elemental Co), so measurements at 40 and 30 $\mathrm{kOe}$ were used to determine the intrinsic magnetic susceptibility (see Experimental Section). The magnetic susceptibility (Figure 9) showed a broad maximum centered at around $270 \mathrm{~K}$, with a peak in the first derivative $\mathrm{d}(\chi \mathrm{T}) / \mathrm{d} T$, which we equate to $T_{\mathrm{N}}$, at $180(20) \mathrm{K}$. These features are typical for two-dimensional systems. ${ }^{6,31,32}$ The observed $T_{\mathrm{N}}$ is too high for Curie or Weiss constants to be extracted from this temperature regime.

A total of $2.0 \mathrm{~g}$ of $\mathrm{Sr}_{2} \mathrm{CoO}_{2} \mathrm{Cu}_{2} \mathrm{Te}_{2}$ was measured using PND at several temperatures in the range $1.7-300 \mathrm{~K}$ in order to understand the magnetic ordering behavior as a function of temperature. Antiferromagnetic ordering peaks appeared on cooling, which were indexed on a $\sqrt{ } 2 a \times \sqrt{ } 2 a \times c$ expansion of the unit cell, suggesting that the primary interaction between

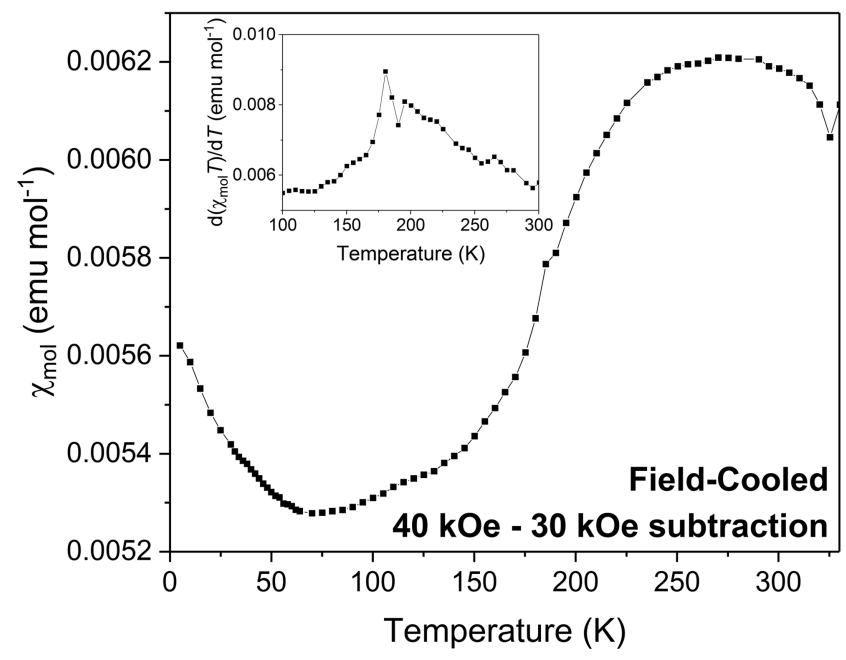

Figure 9. Field-cooled magnetic susceptibility of $\mathrm{Sr}_{2} \mathrm{CoO}_{2} \mathrm{Cu}_{2} \mathrm{Te}_{2}$, measured using a 40-30 kOe subtraction (see Experimental Section). The inset shows the first derivative $\mathrm{d}(\chi T) / \mathrm{d} T$.

the $\mathrm{Co}^{2+}$ moments was nearest-neighbor antiferromagnetic coupling within the $\mathrm{CoO}_{2}$ planes. Symmetry mode analysis in magnetic space group $P 1$ (1.1) showed that all the magnetic intensity could be accounted for using two symmetry modes: $\mathrm{mX3}^{+}(\mathrm{a})$ and $\mathrm{mX}^{+}(\mathrm{a})$. These modes correspond to nearestneighbor antiferromagnetic alignment of spins oriented in the $a b$-plane (Figure S12). These modes can be combined in two ways: collinearly or noncollinearly (Figure S13). These two models are generally indistinguishable using powder diffraction, although the noncollinear model results in a highersymmetry magnetic space group because it maintains tetragonal symmetry. However, in this case, there is evidence that the tetragonal symmetry is broken below $T_{\mathrm{N}}$ (see below); this is often a result of magnetostriction from collinear ordering of magnetic moments with an orbital contribution, ${ }^{5,33}$ therefore, the collinear description was chosen. A model in the $P 2_{1} / c$ (14.75, BNS notation) magnetic space group $\left(P 2_{1} / c\right.$ (14.1.86) using the OG scheme) provided a good fit to the magnetic intensity (Figure 10 and Table 8 ) with an ordered moment per $\mathrm{Co}^{2+}$ ion of $3.60(2) \mu_{\mathrm{B}}$ at $1.7 \mathrm{~K}$.

Variable temperature analysis (Figure S14) revealed that the magnetic peaks do not diminish in intensity at the same rate on heating. This was modeled in the magnetic refinements as a change in the ratio of the two activated distortion modes, which corresponds to a small change in the ratio of the magnetic component parallel to the $a$ direction and the $b$ direction (here $a$ and $b$ refer to the parameters of the magnetic supercell) and, thus, to a slight spin reorientation (Figure 11). Single crystal diffraction measurements would be required to analyze this further.

The temperature dependence of the intensity of the magnetic Bragg peaks gives an estimate for $T_{\mathrm{N}}$ of $175(5) \mathrm{K}$, 


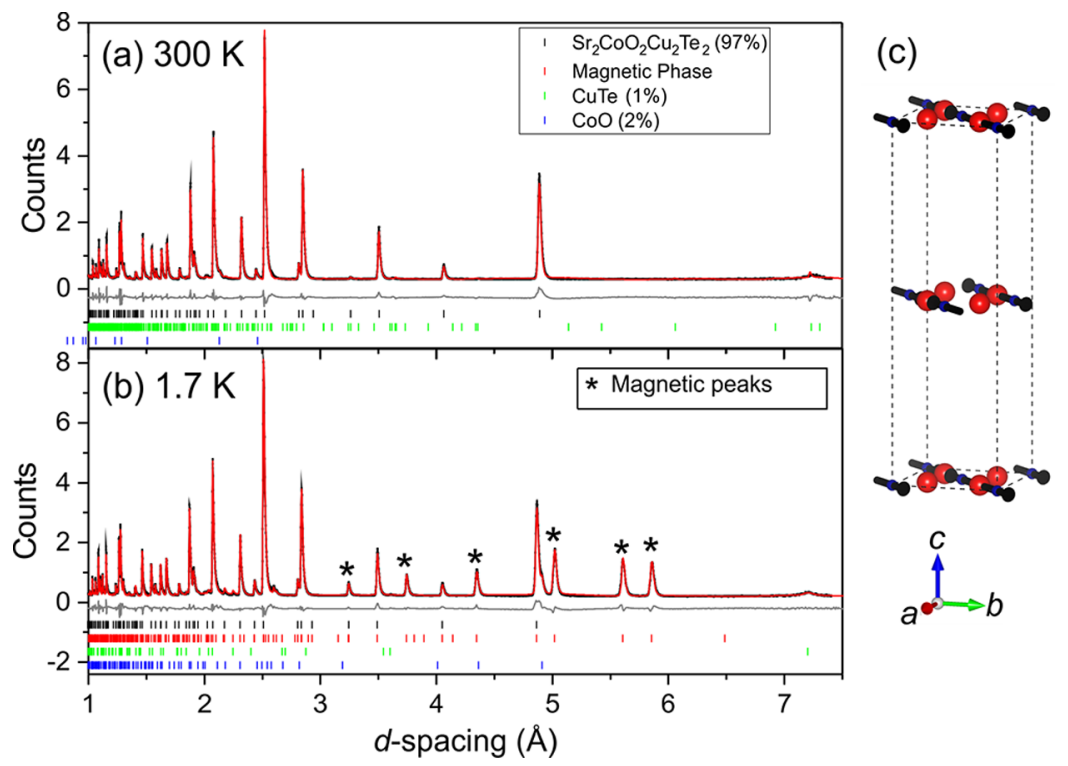

Figure 10. Rietveld refinements of $\mathrm{Sr}_{2} \mathrm{CoO}_{2} \mathrm{Cu}_{2} \mathrm{Te}_{2}$ against PND data measured using the $3 / 8\left(90^{\circ}\right)$ detector bank of WISH at (a) $300 \mathrm{~K}$ and (b) $1.7 \mathrm{~K}$; the * symbols indicate the main magnetic peaks that appear on cooling. (c) Refined magnetic structure at $1.7 \mathrm{~K}$; for clarity, only the Co atoms (small blue circles) and $\mathrm{O}$ atoms (large red circles) are shown.

Table 8. Refined Parameters for the Magnetic Ordering of $\mathrm{Sr}_{2} \mathrm{CoO}_{2} \mathrm{Cu}_{2} \mathrm{Te}_{2}$

$\begin{array}{ll}\text { radiation } & \text { neutron, ToF } \\ \text { diffractometer } & \text { WISH } \\ \text { temp }(\mathrm{K}) & 1.7 \\ \text { magnetic space group (BNS scheme) } & P 2_{1} / c(14.75) \\ \mu_{a}\left(\mu_{\mathrm{B}}\right) & 2.90(2) \\ \mu_{b}\left(\mu_{\mathrm{B}}\right) & 2.14(1) \\ |\mu|\left(\mu_{\mathrm{B}}\right) & 3.60(2) \\ R_{\mathrm{wp}}(\%) & 6.600\end{array}$

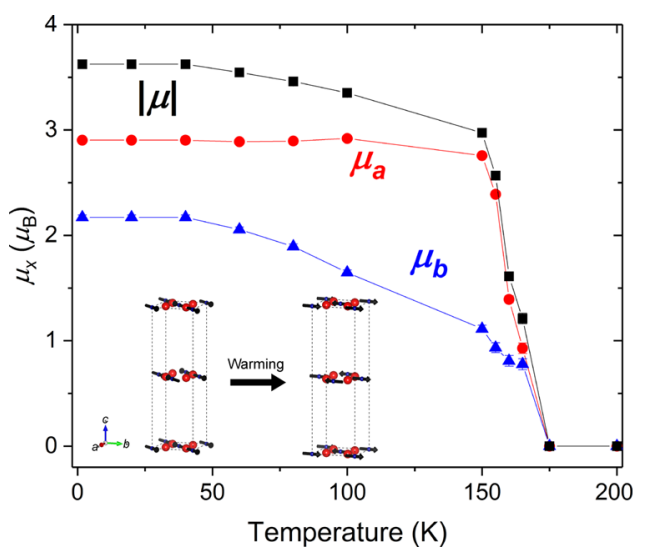

Figure 11. Refined magnetic moment of $\mathrm{Sr}_{2} \mathrm{CoO}_{2} \mathrm{Cu}_{2} \mathrm{Te}_{2}$, shown as both the magnitude $(|\mu|)$ and divided into the components of the magnetic moment in each crystallographic direction (defined using the magnetic unit cell). Data obtained from refinement against WISH data; the refined uncertainties are smaller than the points on the graph and the lines are guides to the eye. The inset demonstrates the effect of the reorientation (albeit much exaggerated).

consistent with our interpretation that the maximum in the derivative of the magnetic susceptibility (Figure 9) corresponds to the long-range ordering, and the broad susceptibility maximum above this temperature arises from short-range correlations that precede long-range order on further cooling.
The refined ordered moment $\left(3.60(2) \mu_{\mathrm{B}}\right)$ is larger than that expected from a spin-only contribution to the magnetic moment $\left(3 \mu_{\mathrm{B}}\right.$ without allowing for any reduction for covalency) for high-spin $\mathrm{d}^{7} \mathrm{Co}^{2+}$. This strongly implies a significant unquenched orbital contribution to the magnetic moment, as observed for $\mathrm{Sr}_{2} \mathrm{CoO}_{2} \mathrm{Cu}_{2} \mathrm{~S}_{2},{ }^{5} \mathrm{Ba}_{2} \mathrm{CoO}_{2} \mathrm{Cu}_{2} \mathrm{~S}_{2}$, $\mathrm{Sr}_{2} \mathrm{CoO}_{2} \mathrm{Ag}_{2} \mathrm{Se}_{2}$, ${ }^{6}$ and $\mathrm{Ba}_{2} \mathrm{CoO}_{2} \mathrm{Ag}_{2} \mathrm{Se}_{2}$. ${ }^{6}$ Smura et al. ${ }^{5}$ noted that the orbital contribution in an octahedral $\mathrm{Co}^{2+}$ environment (such as in $\mathrm{CoO})^{34}$ is significant, but it is quenched on mild distortions from this environment ${ }^{35,36}$ (e.g., as in $\left.\mathrm{La}_{2} \mathrm{CoO}_{4}\right) \cdot{ }^{37}$ However, significantly distending the $\mathrm{CoO}_{4} \mathrm{~S}_{2}$ octahedron causes the ordered moment to recover, and the total moment exceeds that of $\mathrm{CoO}$ when the coordination environment approaches square planar. $^{5}$

Plotting the $\mathrm{Co}-X / \mathrm{Co}-\mathrm{O}$ bond length ratio $(X=$ halide or chalcogenide) against ordered moment allows for the ordered moment of distorted octahedral systems of $\mathrm{Co}^{2+}$ to be predicted, as was shown for $\mathrm{Sr}_{2} \mathrm{CoO}_{2} \mathrm{Ag}_{2} \mathrm{Se}_{2}$ and $\mathrm{Ba}_{2} \mathrm{CoO}_{2} \mathrm{Ag}_{2} \mathrm{Se}_{2}$. ${ }^{6}$ However, the ordered moment of $\mathrm{Sr}_{2} \mathrm{CoO}_{2} \mathrm{Cu}_{2} \mathrm{Te}_{2}$ is somewhat below what might be expected from its $\mathrm{Co}-\mathrm{X} / \mathrm{Co}-\mathrm{O}$ ratio. However, this uses bond lengths that do not take account of the differences in the size of the chalcogenide anion. In the analysis in refs 5 and 6, the size of the nonoxide anions, $X(\mathrm{~S}, \mathrm{Se}, \mathrm{Cl}, \mathrm{Br})$, have been largely comparable due to the $3 d$ contraction, but $\mathrm{Te}^{2-}$ is significantly larger. If a "normalised" Co- $X$ value is used that normalizes the ionic radii of the chalcogenides or halides to the sulfide radius using the values tabulated by Shannon, ${ }^{18}$ the $\mathrm{Sr}_{2} \mathrm{CoO}_{2} \mathrm{Cu}_{2} \mathrm{Te}_{2}$ ordered moment fits well to the established trend (Figure 12).

Low Temperature Structural Distortion in $\mathrm{Sr}_{2} \mathrm{CoO}_{2} \mathrm{Cu}_{2} \mathrm{Te}_{2}$. Comparison of synchrotron PXRD patterns of $\mathrm{Sr}_{2} \mathrm{CoO}_{2} \mathrm{Cu}_{2} \mathrm{Te}_{2}$ at room temperature and $100 \mathrm{~K}$ (Figure 13 compares the 200/ 020 peaks) revealed a small peak splitting in the $100 \mathrm{~K}$ data, which we model as a lowering of symmetry from tetragonal $I 4 / \mathrm{mmm}$ to orthorhombic Immm, similar to that found for $\mathrm{Sr}_{2} \mathrm{CoO}_{2} \mathrm{Cu}_{2} \mathrm{~S}_{2}{ }^{5}$ The difference in $a$ and $b$ in the $100 \mathrm{~K}$ data is 0.00211 (1) $\AA$ (i.e., $\sim 0.05 \%$; see Table S5 for the refined $I m m m$ model). 


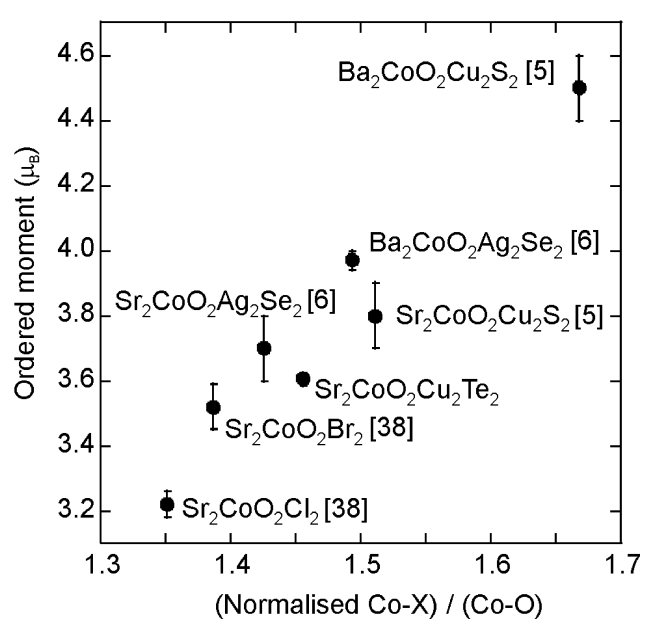

Figure 12. Ordered magnetic moment of $\mathrm{Co}^{2+}$ as a function of the coordination geometry for a series of compounds with distended octahedral $\mathrm{CoO}_{4} X_{2}$ environments $\left(X=\right.$ halide or chalcogenide) ${ }^{5,6,38}$ The Co- $X$ distances have been normalized (see text) to take account of the different radii of the anions.

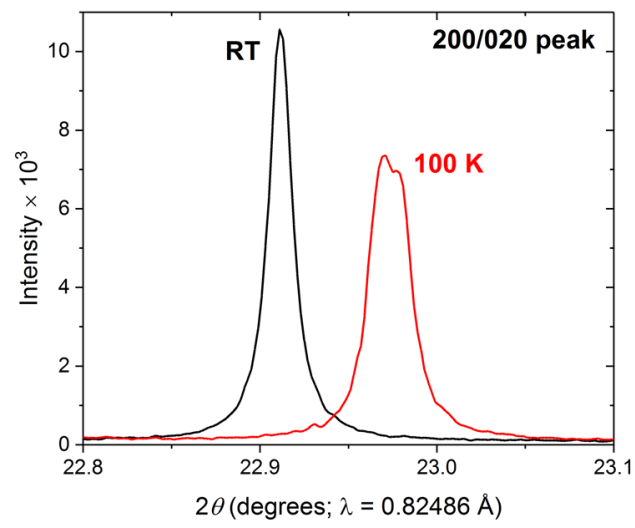

Figure 13. Comparison of the $200 / 020$ peak of $\mathrm{Sr}_{2} \mathrm{CoO}_{2} \mathrm{Cu}_{2} \mathrm{Te}_{2}$ at RT and $100 \mathrm{~K}$. PXRD data obtained using the MAC detector at the I11 beamline (see Figure S15 and Table S5).

Smura et al. suggested that a similar orthorhombic distortion observed for $\mathrm{Sr}_{2} \mathrm{CoO}_{2} \mathrm{Cu}_{2} \mathrm{~S}_{2}$ and $\mathrm{Ba}_{2} \mathrm{CoO}_{2} \mathrm{Cu}_{2} \mathrm{~S}_{2}$ arose from the cooperative coupling of the crystallographic distortion to the orbitally enhanced ordered magnetic moment. ${ }^{5,33}$ The magnetic moment of $\mathrm{Sr}_{2} \mathrm{CoO}_{2} \mathrm{Cu}_{2} \mathrm{Te}_{2}$ also has a significant orbital contribution, so it is likely that the orthorhombic distortion of $\mathrm{Sr}_{2} \mathrm{CoO}_{2} \mathrm{Cu}_{2} \mathrm{Te}_{2}$ arises from a similar magnetostriction. The orthorhombic distortion of $\mathrm{Sr}_{2} \mathrm{CoO}_{2} \mathrm{Cu}_{2} \mathrm{Te}_{2}$ (parametrized by $(b / a)-1: 0.000509(4))$ is larger than for $\left.\mathrm{Sr}_{2} \mathrm{CoO}_{2} \mathrm{Cu}_{2} \mathrm{~S}_{2}(0.00024(2))\right)^{5}$ but smaller than for $\mathrm{Ba}_{2} \mathrm{CoO}_{2} \mathrm{Cu}_{2} \mathrm{~S}_{2}(0.002127(7)){ }^{5}$ This suggests that the orbital contribution to the magnetic moment might not be the sole contributor to the size of the orthorhombic distortion: the identity of the chalcogenide ion may be important. Further investigation is likely to be required to understand this further.

\section{CONCLUSIONS}

The syntheses of $\mathrm{Sr}_{2} \mathrm{MnO}_{2} \mathrm{Cu}_{2-x} \mathrm{Te}_{2}(x=0.18(2), 0.42(2))$ and $\mathrm{Sr}_{2} \mathrm{CoO}_{2} \mathrm{Cu}_{2} \mathrm{Te}_{2}$ have been reported for the first time, and their magnetic behavior is characterized in detail. $\mathrm{Sr}_{2} \mathrm{CoO}_{2} \mathrm{Cu}_{2} \mathrm{Te}_{2}$ containing solely $\mathrm{Co}^{2+}$ shows magnetic behavior consistent with that of isostructural analogues and is resistant to oxidation by deintercalation of $\mathrm{Cu}$. In contrast, when synthesized at high temperature in the presence of sufficient $\mathrm{Cu}$ to fill all the tetrahedral sites in the telluride layer, the $\mathrm{Mn}$ analogue, $\mathrm{Sr}_{2} \mathrm{MnO}_{2} \mathrm{Cu}_{1.82(2)} \mathrm{Te}_{2}$, has a significant (9(1) $\%) \mathrm{Cu}$ deficiency associated with the facile partial oxidation of $\mathrm{Mn}$ above the +2 state, although the $\mathrm{Cu}$ deficiency is much less than the $25 \%$ obtained in the sulfide and selenide analogues under similar synthetic conditions. This presumably reflects the fact that the unit cell expansion required to accommodate the larger telluride ion enforces a larger $\mathrm{Mn}-\mathrm{O}$ distance than with the smaller chalcogenides and, hence, enforces a lower $\mathrm{Mn}$ oxidation state. In this compound there is no magnetic long-range order, and there is evidence for spin-glass-like behavior, presumably resulting from the frustration arising from the disorder inherent in the mixed valence, although there is a Warren-like magnetic peak in the low temperature neutron diffractogram, indicative of short-range magnetic order. Chemical oxidation at ambient temperatures may be used to tune the $\mathrm{Mn}$ oxidation state and turn on long-range magnetic ordering in $\mathrm{Sr}_{2} \mathrm{MnO}_{2} \mathrm{Cu}_{1.58(2)} \mathrm{Te}_{2}$ with a $\mathrm{Mn}$ oxidation state of $\mathrm{Mn}^{2.42(2)+}$. This compound is in the regime where in-plane ferromagnetic coupling occurs resulting from $\mathrm{Mn}$ mixed-valence with a ratio of $\mathrm{Mn}^{2+} / \mathrm{Mn}^{3+}$ close to $1: 1$, so magnetic long-range-order is turned on by the chemical oxidation to produce a state similar to that in oxide selenide analogues.

\section{ASSOCIATED CONTENT}

Supporting Information

The Supporting Information is available free of charge on the ACS Publications website at DOI: 10.1021/acs.inorgchem.9b00919.

Rietveld fits and results, further analysis of magnetization data, as well as Figures S1-S16 and Tables S1-S5 (PDF)

Tables S6 and S7 (PDF)

\section{AUTHOR INFORMATION}

\section{Corresponding Author}

*E-mail: simon.clarke@chem.ox.ac.uk.

ORCID ${ }^{\circ}$

Simon J. Clarke: 0000-0003-4599-8874

\section{Author Contributions}

J.N.B. and D.R.P. synthesized the samples and collected and analyzed the experimental data with help from S. J. Cassidy, D.N.W., and X.X.; S. J. Clarke, D.R.P., and J.N.B. conceived the project; and S. J. Clarke and J.N.B. wrote the paper with input from the other authors.

\section{Notes}

The authors declare no competing financial interest.

\section{ACKNOWLEDGMENTS}

We thank the UK EPSRC for funding (Grants EP/E025447/1, $\mathrm{EP} / \mathrm{P018874/1}$, and EP/M020517/1) and for studentship support; the ISIS pulsed neutron and muon source (RB170084) and the Diamond Light Source Ltd (EE13284 and EE18786) for the award of beam time; Diamond Light Source Ltd for studentship support for J.N.B. We thank Dr. P. Manuel and Dr. F. Orlandi for assistance on WISH and Dr. C. Murray, Dr. S. Day, and Dr. A. Baker for assistance on I11. 


\section{REFERENCES}

(1) Clarke, S. J.; Adamson, P.; Herkelrath, S. J. C.; Rutt, O. J.; Parker, D. R.; Pitcher, M. J.; Smura, C. F. Structures, physical properties, and chemistry of layered oxychalcogenides and oxypnictides. Inorg. Chem. 2008, 47, 8473-8486.

(2) Zhu, W. J.; Hor, P. H. Unusual Layered Transition-Metal Oxysulfides: $\mathrm{Sr}_{2} \mathrm{Cu}_{2} \mathrm{MO}_{2} \mathrm{~S}_{2}(M=\mathrm{Mn}, \mathrm{Zn})$. J. Solid State Chem. 1997, 130, 319-321.

(3) Zhu, W. J.; Hor, P. H.; Jacobson, A. J.; Crisci, G.; Albright, T. A.; Wang, S. H.; Vogt, T. $A_{2} \mathrm{Cu}_{2} \mathrm{CoO}_{2} \mathrm{~S}_{2}(A=\mathrm{Sr}, \mathrm{Ba})$, A Novel Example of a Square-Planar $\mathrm{CoO}_{2}$ Layer. J. Am. Chem. Soc. 1997, 119, 1239812399.

(4) Adamson, P.; Hadermann, J.; Smura, C. F.; Rutt, O. J.; Hyett, G.; Free, D. G.; Clarke, S. J. Competing Magnetic Structures and the Evolution of Copper Ion/Vacancy Ordering with Composition in the Manganite Oxide Chalcogenides $\mathrm{Sr}_{2} \mathrm{MnO}_{2} \mathrm{Cu}_{1.5}\left(\mathrm{~S}_{1-x} \mathrm{Se}_{x}\right)_{2}$. Chem. Mater. 2012, 24, 2802-2816.

(5) Smura, C. F.; Parker, D. R.; Zbiri, M.; Johnson, M. R.; Gál, Z. A.; Clarke, S. J. High-Spin Cobalt(II) Ions in Square Planar Coordination: Structures and Magnetism of the Oxysulfides $\mathrm{Sr}_{2} \mathrm{CoO}_{2} \mathrm{Cu}_{2} \mathrm{~S}_{2}$ and $\mathrm{Ba}_{2} \mathrm{CoO}_{2} \mathrm{Cu}_{2} \mathrm{~S}_{2}$ and Their Solid Solution. J. Am. Chem. Soc. 2011, 133, 2691-2705.

(6) Herkelrath, S. J. C; Blandy, J. N.; Clarke, S. J. Magnetic ordering in the layered oxyselenides $\mathrm{Sr}_{2} \mathrm{CoO}_{2} \mathrm{Ag}_{2} \mathrm{Se}_{2}$ and $\mathrm{Ba}_{2} \mathrm{CoO}_{2} \mathrm{Ag}_{2} \mathrm{Se}_{2}$. J. Solid State Chem. 2018, 264, 119-123.

(7) Blandy, J. N.; Abakumov, A. M.; Christensen, K. E.; Hadermann, J.; Adamson, P.; Cassidy, S. J.; Ramos, S.; Free, D. G.; Cohen, H.; Woodruff, D. N.; Thompson, A. L.; Clarke, S. J. Soft chemical control of the crystal and magnetic structure of a layered mixed valent Manganite oxide sulfide. APL Mater. 2015, 3, 041520.

(8) Adamson, P. Doctoral Thesis, University of Oxford, 2010.

(9) Blandy, J. N.; Boskovic, J. C.; Clarke, S. J. Synthesis and Magnetic Structure of the layered manganese oxide selenide $\mathrm{Sr}_{2} \mathrm{MnO}_{2} \mathrm{Ag}_{1.5} \mathrm{Se}_{2}$. J. Solid State Chem. 2017, 245, 61-66.

(10) Kanashiro, T.; Kishimoto, Y.; Ohno, T.; Michihiro, Y. NMR study of mobile ions in $\mathrm{Cu}_{x} \mathrm{Se}$ and $\mathrm{Cu}_{x} \mathrm{~S}$. Solid State Ionics 1990, 40$41,308-311$.

(11) Johnson, D. A. Some Thermodynamic Aspects of Inorganic Chemistry; Cambridge University Press, 1968.

(12) Thompson, S. P.; Parker, J. E.; Potter, J.; Hill, T. P.; Birt, A.; Cobb, T. M.; Yuan, F.; Tang, C. C. Beamline I11 at Diamond: A new instrument for high resolution powder diffraction. Rev. Sci. Instrum. 2009, 80, 075107.

(13) Chapon, L. C.; Manuel, P.; Radaelli, P. G.; Benson, C.; Perrott, L.; Ansell, S.; Rhodes, N. J.; Raspino, D.; Duxbury, D.; Spill, E.; Norris, J. WISH: The New Powder and Single Crystal Magnetic Diffractometer on the Second Target Station. Neutron News 2011, 22, 22-25.

(14) Coelho, A. A., TOPAS Academic, Version 5; Coelho Software, Brisbane, Australia, 2012.

(15) Campbell, B. J.; Stokes, H. T.; Tanner, D. E.; Hatch, D. M. ISODISPLACE : a web-based tool for exploring structural distortions. J. Appl. Crystallogr. 2006, 39, 607-614.

(16) Origin; OriginLab, Northampton, MA, U.S.A., 2019.

(17) Brechtel, E.; Cordier, G.; Schafer, H. Oxidepnictides Preparation and Crystal -Structure of $A_{2} \mathrm{Mn}_{3} B_{2} \mathrm{O}_{2}$ with $A=\mathrm{Sr}$, Ba and $B=$ As, Sb, Bi. Z. Naturforsch., B: J. Chem. Sci. 1979, 34, 777-780.

(18) Shannon, R. D. Revised effective ionic radii and systematic studies of interatomic distances in halides and chalcogenides. Acta Crystallogr., Sect. A: Cryst. Phys., Diffr., Theor. Gen. Crystallogr. 1976, 32, 751-767.

(19) Jin, S.; Chen, X.; Guo, J.; Lei, M.; Lin, J.; Xi, J.; Wang, W.; Wang, W. $\mathrm{Sr}_{2} \mathrm{Mn}_{3} \mathrm{Sb}_{2} \mathrm{O}_{2}$ Type Oxyselenides: Structures, Magnetism, and Electronic Properties of $\mathrm{Sr}_{2} A_{2} \mathrm{O}_{2} \mathrm{M}_{2} \mathrm{Se}_{2}(A=\mathrm{Co}, \mathrm{Mn} ; M=\mathrm{Cu}$, Ag). Inorg. Chem. 2012, 51, 10185-10192.

(20) Goodwin, A. L.; Tucker, M. G.; Dove, M. T.; Keen, D. A. Magnetic Structure of $\mathrm{MnO}$ at $10 \mathrm{~K}$ from Total Neutron Scattering Data. Phys. Rev. Lett. 2006, 96, 047209.
(21) Warren, B. E. X-Ray Diffraction in Random Layer Lattices. Phys. Rev. 1941, 59, 693-698.

(22) Warren, B. E.; Bodenstein, P. The shape of two-dimensional carbon black reflections. Acta Crystallogr. 1966, 20, 602-605.

(23) Brock, S. L.; Raju, N. P.; Greedan, J. E.; Kauzlarich, S. M. The magnetic structures of the mixed layer pnictide oxide compounds $\mathrm{Sr}_{2} \mathrm{Mn}_{3} \mathrm{Pn}_{2} \mathrm{O}_{2}(P n=\mathrm{As}, \mathrm{Sb})$. J. Alloys Compd. 1996, 237, 9-19.

(24) McCabe, E. E.; Stock, C.; Rodriguez, E. E.; Wills, A. S.; Taylor, J. W.; Evans, J. S. O. Weak spin interactions in Mott insulating $\mathrm{La}_{2} \mathrm{O}_{2} \mathrm{Fe}_{2} \mathrm{OSe}_{2}$. Phys. Rev. B: Condens. Matter Mater. Phys. 2014, 89, 100402 .

(25) Zhao, L. L.; Wu, S.; Wang, J. K.; Hodges, J. P.; Broholm, C.; Morosan, E. Quasi-two-dimensional noncollinear magnetism in the Mott insulator $\mathrm{Sr}_{2} \mathrm{~F}_{2} \mathrm{Fe}_{2} \mathrm{OS}_{2}$. Phys. Rev. B: Condens. Matter Mater. Phys. 2013, 87, 020406.

(26) Belov, N. V.; Neronova, N. N.; Smirnova, T. S. The 1651 Shubnikov Groups. Acta Crystallogr. 1957, 10, 848-848.

(27) Litvin, D. B., Ed. In Magnetic Group Tables; International Union of Crystallography: Chester, England, 2013.

(28) Opechowski, W.; Guccione, R. Magnetism; Academic Press: New York, 1965.

(29) Gál, Z. A.; Rutt, O. J.; Smura, C. F.; Overton, T. P.; Barrier, N.; Clarke, S. J.; Hadermann, J. Structural Chemistry and Metamagnetism of an Homologous Series of Layered Manganese Oxysulfides. J. Am. Chem. Soc. 2006, 128, 8530-8540.

(30) Argyriou, D. N.; Bordallo, H. N.; Campbell, B. J.; Cheetham, A. K.; Cox, D. E.; Gardner, J. S.; Hanif, K.; dos Santos, A.; Strouse, G. F. Charge ordering and phase competition in the layered perovskite $\mathrm{LaSr}_{2} \mathrm{Mn}_{2} \mathrm{O}_{7}$. Phys. Rev. B: Condens. Matter Mater. Phys. 2000, 61, 15269-15276.

(31) He, J. B.; Wang, D. M.; Shi, H. L.; Yang, H. X.; Li, J. Q.; Chen, G. F. Synthesis, structure, and magnetic properties of the layered iron oxychalcogenide $\mathrm{Na}_{2} \mathrm{Fe}_{2} \mathrm{Se}_{2} \mathrm{O}$. Phys. Rev. B: Condens. Matter Mater. Phys. 2011, 84, 205212.

(32) Ni, N.; Climent-Pascual, E.; Jia, S.; Huang, Q.; Cava, R. J. Physical properties and magnetic structure of the layered oxyselenide $\mathrm{La}_{2} \mathrm{O}_{3} \mathrm{Mn}_{2} \mathrm{Se}_{2}$. Phys. Rev. B: Condens. Matter Mater. Phys. 2010, 82, 214419.

(33) Goodenough, J. B. Magnetism and the Chemical Bond; Interscience: New York/London, 1963.

(34) Jauch, W.; Reehuis, M.; Bleif, H. J.; Kubanek, F.; Pattison, P. Crystallographic symmetry and magnetic structure of CoO. Phys. Rev. B: Condens. Matter Mater. Phys. 2001, 64, 052102.

(35) Hansteen, O. H.; Fjellvåg, H.; Hauback, B. C. Crystal Structure and Magnetic Properties of $\mathrm{La}_{2} \mathrm{Co}_{2} \mathrm{O}_{5}$. J. Solid State Chem. 1998, 141, 411-417.

(36) Hansteen, O. H.; Fjellvåg, H.; Hauback, B. C. Crystal structure, thermal and magnetic properties of $\mathrm{La}_{4} \mathrm{Co}_{3} \mathrm{O}_{9}$. Phase relations for $\mathrm{La}_{4} \mathrm{Co}_{3} \mathrm{O}_{10-\delta}(0.00 \leq \delta \leq 1.00)$ at $673 \mathrm{~K}$. J. Mater. Chem. 1998, 8, 2089-2093.

(37) Yamada, K.; Matsuda, M.; Endoh, Y.; Keimer, B.; Birgeneau, R. J.; Onodera, S.; Mizusaki, J.; Matsuura, T.; Shirane, G. Successive antiferromagnetic phase transitions in single-crystal $\mathrm{La}_{2} \mathrm{CoO}_{4}$. Phys. Rev. B: Condens. Matter Mater. Phys. 1989, 39, 2336-2343.

(38) Knee, C. S.; Weller, M. T. Neutron diffraction study of crystal structure and antiferromagnetic order in $\mathrm{Sr}_{2} \mathrm{CoO}_{2} X_{2}(X=\mathrm{Cl}, \mathrm{Br})$. Phys. Rev. B: Condens. Matter Mater. Phys. 2004, 70, 144406. 